\title{
Electronic cigarettes: a task force report from the European Respiratory Society
}

\author{
Robert Bals ${ }^{1}$, Jeanette Boyd ${ }^{2}$, Susanna Esposito ${ }^{3}$, Robert Foronjy ${ }^{4}$, \\ Pieter S. Hiemstra (10 ${ }^{5}$, Carlos A. Jiménez-Ruiz ${ }^{6}$, Paraskevi Katsaounou (107, \\ Anne Lindberg ${ }^{8}$, Carlos Metz ${ }^{1}$, Wolfgang Schober ${ }^{9}$, Avrum Spira ${ }^{10}$ and \\ Francesco Blasi ${ }^{11}$
}

\begin{abstract}
Affiliations: ${ }^{1}$ Dept of Internal Medicine V - Pulmonology, Allergology and Critical Care Medicine, Saarland University, Homburg, Germany. ${ }^{2}$ European Lung Foundation (ELF), Sheffield, UK. ${ }^{3}$ Pediatric Clinic, Dept of Surgical and Biomedical Sciences, Università degli Studi di Perugia, Perugia, Italy. ${ }^{4}$ Pulmonary and Critical Care Medicine, SUNY Downstate Medical Center, New York, NY, USA. ${ }^{5}$ Dept of Pulmonology, Leiden University Medical Center, Leiden, The Netherlands. ${ }^{6}$ Smoking Cessation Service, Madrid, Spain. ${ }^{7} 1$ st ICU Evangelismos Hospital, National Kapodistrian University of Athens, Athens, Greece. ${ }^{8}$ Dept of Public Health and Clinical Medicine, Division of Medicine, Umeå University, Umeå, Sweden. ${ }^{9}$ Bavarian Health and Food Safety Authority, Dept of Chemical Safety and Toxicology, Munich, Germany. ${ }^{10}$ Boston University School of Medicine, Boston, MA, USA. ${ }^{11}$ Dept of Pathophysiology and Transplantation, Università degli Studi di Milano, Internal Medicine Department, Respiratory Unit and Regional Adult Cystic Fibrosis Center, IRCCS Fondazione Cà Granda Ospedale Maggiore Policlinico, Milan, Italy.
\end{abstract}

Correspondence: Robert Bals, Dept of Internal Medicine V - Pulmonology, Allergology and Critical Care Medicine, Saarland University Medical Center, 66421 Homburg, Germany. E-mail: robert.bals@uuks.eu

@ERSpublications

Electronic cigarettes are the object of intense research with the goal to define the potential harmful effects for human health http://ow.ly/gTFN30mIYjD

Cite this article as: Bals R, Boyd J, Esposito S, et al. Electronic cigarettes: a task force report from the European Respiratory Society. Eur Respir J 2019; 53: 1801151 [https://doi.org/10.1183/13993003.011512018].

ABSTRACT There is a marked increase in the development and use of electronic nicotine delivery systems or electronic cigarettes (ECIGs). This statement covers electronic cigarettes (ECIGs), defined as "electrical devices that generate an aerosol from a liquid" and thus excludes devices that contain tobacco. Database searches identified published articles that were used to summarise the current knowledge on the epidemiology of ECIG use; their ingredients and accompanied health effects; second-hand exposure; use of ECIGs for smoking cessation; behavioural aspects of ECIGs and social impact; in vitro and animal studies; and user perspectives.

ECIG aerosol contains potentially toxic chemicals. As compared to conventional cigarettes, these are fewer and generally in lower concentrations. Second-hand exposures to ECIG chemicals may represent a potential risk, especially to vulnerable populations. There is not enough scientific evidence to support ECIGs as an aid to smoking cessation due to a lack of controlled trials, including those that compare ECIGs with licenced stop-smoking treatments. So far, there are conflicting data that use of ECIGs results in a renormalisation of smoking behaviour or for the gateway hypothesis. Experiments in cell cultures and animal studies show that ECIGs can have multiple negative effects. The long-term effects of ECIG use are unknown, and there is therefore no evidence that ECIGs are safer than tobacco in the long term. Based on current knowledge, negative health effects cannot be ruled out.

This document was endorsed by the European Respiratory Society Executive Committee and Science Council on October 292018.

Received: June 192018 | Accepted after revision: Aug 092018

Copyright OERS 2019 


\section{Introduction}

Smoking of tobacco products is one of the major preventable risk factors for death related to cardiovascular, neoplastic, infectious and respiratory diseases. There has recently been a marked increase in the development and use of electronic nicotine delivery systems or electronic cigarettes (ECIGs). This statement covers ECIGs, defined as "electrical devices that generate an aerosol from a liquid" and thus excludes devices that contain tobacco (such as heat-not-burn tobacco products). ECIGs contain nicotine, propylene glycol and/or glycerine, flavourings (>8000 different types are available), water, alcohol and other substances, which are vapourised and delivered to the lungs. Analysis of published literature demonstrates that worldwide research activity on ECIGs has been and still is increasing [1].

An intense discussion is ongoing on the potential benefits and harms of the use of ECIGs. Related to the European Respiratory Society (ERS) view that "human lungs are made to breathe clean air and any substance inhaled long term may be detrimental”, many publications provide data on the toxicology and harm-causing effects of ECIGs. The discussion on ECIGs focuses on the questions whether changing from smoking of tobacco products to ECIGs could reduce harm. A large number of publications address this approach. The main issues analysed in this discussion are: 1) health concerns related to exposure to ECIG constituents, including nicotine; 2) risks from second-hand emissions; 3) the role of ECIGs as a gateway, particularly to the young, both for tobacco smoking and nicotine dependence; and 4) their potential role as a smoking cessation tool.

The Forum of International Respiratory Societies (FIRS) issued a position statement on ECIGs asking for more independent studies on the benefits and potential harms of ECIG use, and a prudent restriction of the usage of these products at least until their safety can be established [2].

As this scientific field is quite young, a potential bias might be introduced by active authors or groups that have published multiple papers in a specific direction. In addition, specific authors have a documented conflict of interest with the ECIG industry (relevant for references [39, 40, 52, 53, 91, 104, 105, 108, 109, $110,153,180,185,210,211,217,218,220,247,279,282])$.

On this basis, the ERS has established a task force to collect, analyse and integrate the current knowledge on ECIGs, and to provide an evaluation of the subject for various stakeholders, including physicians, scientists, patients, users and policy makers. The task force group was geographically balanced and experts from 10 different European and American countries were included. A potential conflict of interest, especially with the tobacco or ECIG industry, was evaluated by using the International Committee of Medical Journal Editors form according to ERS guidelines. No such conflicts of interest were identified.

\section{Methods}

The task force collected publications on research published in peer-reviewed journals and publicly available documents on ECIGs. Eligible studies were original papers with empirical data including experimental studies, including preclinical studies (work on molecules, cells, animals); observational studies (including case-control, cohort and cross-sectional studies); case reports and case series; clinical trials using ECIGs; and systematic reviews with or without meta-analysis.

Only studies in the English language published before August 2016 were included (except two non-English papers). Later publications that were relevant were added as the report was finalised. If individual papers were not identified by the search strategy, experts from the task force could propose the inclusion of studies from other sources. The task force conducted literature searches in the National Library of Medicine's PubMed electronic database (MEDLINE, PubMed), Scopus, PsycINFO and Embase. The database searches were performed by $\mathrm{CM}$ and $\mathrm{RB}$ and all results were put in a reference management system (Mendeley team package; Elsevier, Amsterdam, the Netherlands). All other members of the task force were eligible to include references. Based on the database searches, a total number 2271 of publications was identified. The publications were allocated to eight working groups of the task force. The allocation was supervised by the two co-chairs (RB, FB). The full-text publications were obtained and inserted into a web-based database system. The analysis and discussion of each topic area were performed both in face-to-face meetings and web-based conferences. During this process, documents were excluded (nonsystematic reviews, small observational studies, commentaries) and 289 references included in the present publication.

For the identification of user-specific items, the work groups responsible for identifying and reviewing the literature for each chapter of the manuscript were asked to identify specific articles that contained user perspectives particularly around their values (attitudes, beliefs and motivations) for using ECIGs, the aim being to complement the studies identified from the systematic review to provide further insight into user-centred values and preferences in relation to ECIG use. A total of 35 articles were identified. These articles were then passed to the European Lung Foundation (ELF) to review and analyse using thematic 
content analysis. Following review, 16 articles were selected by ELF as within the scope of the manuscript and having content relating to user values and preferences. A summary of the themes from the articles identified was written by ELF to produce the user-focused section of the manuscript.

The initial draft of the manuscript was prepared by the co-chairs together with members of the working groups. The manuscript was reviewed, edited and approved by all authors prior to submission. Despite the intense literature search, this paper is not a systematic review.

\section{Epidemiology of ECIG use}

ECIG use among teenagers and young adults

Several studies have shown that awareness and use of ECIGs has been increasing in teenagers. Dual cigarette and ECIG use increased from $0.8 \%$ in February 2010 to $1.9 \%$ in June 2011 ( $p=0.03$ ) in a United States high-school population; $>80 \%$ of the ECIGs users also used cigarettes [3]. In Korea, 4341 students from middle and high school (mean age 14.0 and 16.5 years, respectively) responded to a questionnaire in 2008; $10.2 \%$ had seen or heard of ECIGs, but only $0.5 \%$ had tried them [4]. The Florida Youth Tobacco Survey was a self-completed, school-based paper survey that has been administered to a random sample (>12000 students) of public middle- and high-school students annually since 1998 in the state of Florida, USA. In 2011, 6.0\% of high school students had tried ECIGs, while in 2012 the proportion increased by $40 \%$ to $8.4 \%$; the use of ECIGs within the past 30 days was $3.1 \%$ and $3.5 \%$, respectively [5]. The US Population Assessment of Tobacco and Health (PATH) study, a nationally representative study conducted in 2013 and 2014, which included 13651 youths aged between 12 and 17 years, found that $13.4 \%$ had ever used an ECIG, 3.1\% had used ECIGs in the past 30 days and $0.2 \%$ used them daily [6]. Numerous other studies show similar results, which indicate that adolescents use or experiment with ECIGs [4, 7-14]. A number of studies investigated risk factors for ECIG use in teenagers and the social levels of school forms were associated with ECIG use frequency [15]. A strong predictor of frequency of ECIG use is cigarette smoking. Most youths who use ECIGs are also cigarette smokers [16]. Among never-smokers who use ECIGs, most only use them 1-2 days per month, and many use nicotine-free ECIGs. The designation "nicotine-free" was based on information supplied by the manufacturers. Among cigarette smokers the frequency of past 30-day use of ECIGs is much higher. Other risk factors include family smoking behaviour [17] or current cigarette smoking [10, 18]. These studies indicate that ECIG use among teenagers and young adults has increased over the past few years [16, 19].

\section{ECIG use among adults}

A large number of studies show that the use and awareness of ECIGs has been increasing in adults over the past few years. In 2012, the prevalence of use was still low and ECIG use was associated with lower age and better education [20]. Larger studies are sparse and often compare results from several countries [21]. Data regarding ECIG use was collected in 2012 from 25 European countries, with the highest prevalence in Denmark (4.2\%) and lowest in Portugal and Lithuania (0.6\%) [22]. More recent data from 2017 from 28 European Union (EU) member states indicated that since 2014, the proportion of those who have at least tried ECIGs has increased (12\% in 2014 versus 15\% in 2017). However, the proportion of adults currently using ECIGs appears to remain stable at $2 \%$ of the EU population [23]. Studies involving French college students revealed a prevalence of ever-use and current use of ECIGs of $23.0 \%$ and $5.7 \%$ respectively, while prevalence of the combined use of conventional cigarettes and ECIGs was 14.5\% [24]. Awareness was high and variable in a survey involving 10 countries [25]. In addition, a telephone survey in France showed similar data [26], as did related studies in other European countries [27]. There have been repeated surveys in USA comparing ECIG use in 2010 and 2013 in study samples of 2505-4170 individuals. During this period, ever-use of ECIG increased among current and former cigarette smokers (9.8-36.5\% and 2.5-9.6\%, respectively), while it remained at a similar level among never-smokers (1.3$1.2 \%$ [8]. Several studies showed increasing use and awareness of ECIGs, especially in countries where they can be obtained legally and companies have open market access [28-36]. The number of tobacco cigarettes smoked per day and high income was associated with ECIG use [30, 37]. Repeated cross-sectional surveys in USA during the years 2010, 2011, 2012 and 2013 included $>3000$ individuals aged $\geqslant 18$ years in each sample. Both ever- and current use of ECIGs increased, from $1.8 \%$ to $13.0 \%$ and $0.3 \%$ to $6.8 \%$, respectively, between 2010 and 2013. Current use of ECIGs, defined as any use within the past 30 days, was associated with smoking status; it was $30.3 \%$ among daily smokers, $5.4 \%$ among former smokers and 5.4\% among never-smokers [34]. The PATH study, which included 45971 adults, reported ECIG use in $6.7 \%$ in the past 30 days and $1.2 \%$ daily [6]. Similar prevalence of ECIG use has been found in patients with cancer $[21,38]$. However, more regular use of ECIGs (weekly or daily) is seen almost exclusively in smokers [39, 40]. It is important to also note that $1.2 \%$ of never-smokers of cigarettes reported having ever used an ECIG in the EU, which is $~ 29.3$ million adults. 
The most common reasons for using ECIGs is to quit or cut down tobacco usage based on the assumption that they are less harmful than other tobacco products, but also that they can be used where smoking is prohibited [24, 41]. In addition, curiosity is a main factor for the use of ECIGs [42, 43]. Individuals with mental health conditions show a high prevalence of ECIG use [44-46]. In addition, it is important to note that there is much discussion over how best to monitor the prevalence of ECIG use [47, 48].

\section{Conclusion}

Taken together, the use of ECIGs has increased over the past decade among both adolescents and adults. Regular use of ECIGs is most common among individuals who are current or former smokers.

\section{In vitro and in vivo animal studies}

A variety of in vitro and in vivo model systems have been used in the evaluation of effects of ECIGs. In many studies, effects of ECIGs were compared to those resulting from exposure to traditional tobacco cigarettes (TCIGs). This section is focused on effects of ECIG liquid and vapour, whereas effects of individual constituents such as nicotine are discussed in the following section on ingredients and health effects.

\section{In vitro model studies on ECIGs}

Different models have been used to study the effect of ECIGs on a variety of cell types. These include studies focusing on the vapour generated by ECIGs, but also studies of e-liquids and individual constituents of ECIGs. Study designs show marked differences with regards to the exposure systems used, including the puffing regimen used.

Cytotoxicity to various cell lines, causing cell death, decreased cell proliferation and increased oxidative stress have been reported [49-51]. Studies using a variety of cell types showed that effects of ECIGs on cell death and changes in gene expression were markedly lower than TCIGs [52-58]. However, it has been documented that ECIGs do cause a variety of adverse cellular effects on a range of cell types. Airway epithelial cells are a principal target for inhaled ECIG vapour, and primary airway epithelial cells are increasingly used in cytotoxicity studies because they are thought to better represent the airway epithelium than the widely used continuous tumour or immortalised cell lines. An overview of the effects of ECIGs on such human primary airway epithelial cells is provided in table 1. The design of such studies differed markedly, and only two used exposure of cells differentiated at the air-liquid interface (ALI) to ECIG vapour [54,60]. Therefore, these studies are discussed in detail. Both studies used the same commercially available culture model system using primary bronchial epithelial cells obtained from a single donor cultured and differentiated at the ALI (EpiAirway; MatTek, Ashland, MA, USA). A study from British American Tobacco [60] showed that exposure to ECIG vapour did not induce cytotoxicity or a decrease in epithelial barrier function, whereas TCIG smoke exposure caused marked effects on these parameters. Moses et al. [54] used a similar approach by exposing cells to aerosols generated by ECIGs (four different ECIGs from one single manufacturer) or smoke generated by TCIGs (3R4F reference cigarettes; University of Kentucky, Lexington, KY, USA) using a commercially available exposure system (Vitrocell, Waldkirch, Germany). Whereas, in line with the study by NeILSON et al. [60], no overt cytotoxicity was noted with ECIGs (as compared to TCIGs), both ECIGs and TCIGs caused similar changes in gene expression. In particular, alterations in expression of genes related to xenobiotic metabolism, oxidative stress, DNA damage, apoptosis and cilia formation and function were noted. While the magnitude of these changes

TABLE 1 Effects of electronic cigarettes (ECIGs) on human airway epithelial cells (HAECs)

HAEC culture system ECIG exposure

Effect

Reference

\begin{tabular}{ccc}
\hline $\begin{array}{c}\text { Type of analysis } \\
\text { Metabolomics }\end{array}$ & ALI & Liquid \\
Transcriptomics & Aerosol \\
Observed changes & $\mathrm{ALI}$ & \\
Oxidative stress & $\mathrm{ALI}$ & Aerosol \\
Ciliary function & $\mathrm{ALI}$ & Aerosol \\
Cytotoxicity & $\mathrm{ALI}$ & Aerosol \\
& $\mathrm{ALI}$ & Aerosol \\
Barrier function & $\mathrm{ALI}$ & Aerosol
\end{tabular}

Change (comparable to TCIG smoke condensate) Change (partly similar to whole TCIG smoke)

Increase (mostly lower than with TCIG smoke) Decrease in gene expression No toxicity Decreased viability No effect on TEER
[59]

$[54,56]$

[54]

$[54,60]$

[56]

[54]

ALI: air-liquid interface; TCIG: tobacco cigarette; TEER: trans-epithelial electrical resistance. ${ }^{\#}$ : HAECs in [56] were exposed at the ALI, but not differentiated at the ALI. 
was higher in TCIGs than in ECIGs, nicotine-containing ECIGs caused more profound changes than ECIGs that did not contain nicotine. The authors noted remarkably similar changes in gene expression in airway epithelial cells derived from bronchial brushes of ECIG users and cultures exposed to ECIGs.

In addition to studies on primary lung epithelial cells, other studies used human immortalised or tumour lung epithelial cells to assess cytotoxic effects, and changes in gene expression or function induced by exposure to extracts of ECIG vapour or ECIG liquid, as shown in studies using A549 [49,57, 58] and BEAS-2B cells [61]. In addition, effects of ECIGs on other cell types have been explored. Such studies showed cytotoxic and other adverse effects of (extracts from) ECIG vapour or e-liquid on human gingival and lung fibroblasts [49, 62], vascular smooth muscle cells [63], embryonic stem cells [64], neutrophils [65] and a macrophage cell line [66], as well as a myocardial cell line [52].

While many studies assessing effects of ECIGs have used cell death, epithelial barrier changes or changes in gene expression related to inflammation $[49,67]$ or oxidative stress $[49,54,56,61]$ as a read-out, fewer studies have explored the effect of ECIGs on tumour development and growth. This is highly relevant, since TCIG smoke has been shown to contain various carcinogens. Heating of ECIG liquid was found to result in the release of carcinogenic substances [68], and ECIG vapour, both with and without nicotine, was found to be cytotoxic and cause DNA strand breaks in keratinocyte and head and neck squamous cancer carcinoma cell lines [69].

In selected studies, the contribution of nicotine to the observed adverse effects was assessed. Those studies showed clearly that effects were not mediated only by nicotine in e-liquid or vapour $[56,57,61,67,69]$. Thousands of ECIG flavours are marketed, but little is known about their toxicity, especially following heating and inhalation. The contribution of such flavourings and of other constituents, including nicotine, is discussed later, showing that more information is needed on the cytotoxic potential of ECIG flavours.

\section{Limitations of in vitro studies}

In vitro studies exploring effects of ECIGs frequently use nondifferentiated, continuous cell lines, such as the A549 lung epithelial cell line. However, in vitro toxicology studies are increasingly using more advanced systems using primary epithelial cells that have been differentiated and are exposed at the ALI (table 1). An important issue in such studies is the consideration of puffing regime, and of deposition efficiency; information on the latter is usually not available. It is therefore difficult to determine whether exposure conditions in vitro can be extrapolated to the situation in ECIG users.

\section{Animal models}

A limited number of animal studies have been used to investigate the effect of ECIGs on the lung and other organs. In a murine model of ovalbumin (OVA)-based asthma, the application of diluted ECIG solution increased airway inflammation illustrated by an increase in eosinophils, levels of type 1 T-helper cell cytokines interleukin (IL)-4, IL-5 and IL-13, OVA-specific IgE, and airway hyperresponsiveness [70]. 4 months' exposure to inhaled nicotine-containing ECIG fluids triggered effects normally associated with the development of a chronic obstructive pulmonary disease (COPD)-like tissue damage in a nicotine-dependent manner [71]. A 7-month cigarette smoke inhalation study (industry sponsored) in C57BL/6 mice showed nicotine-dependent lung inflammation and emphysema after ECIG exposure; however, it was lower than that observed following exposure to smoke from conventional cigarettes [72]. Acute exposure to electronic and conventional cigarettes showed lower, but still measurable adverse effects of ECIGs with regard to barrier disruption and cytokine release [58].

Several studies investigated the effect of ECIG exposure on host defence. One study investigated the effect of exposure to ECIG vapour for 2 weeks, and showed an increased susceptibility to infection with influenza A and Streptococcus pneumoniae [73]. A 4-week exposure to ECIG vapour decreased macrophage and neutrophil antimicrobial function and increased susceptibility in a mouse pneumonia model [74]. Exposure of rats to a commercial ECIG device in whole-body mode showed induction of mutations and activation of carcinogen-bioactivating enzymes [75].

\section{Extrapulmonary effects}

Neonatal mice were exposed to ECIGs for the first 10 days of their life and were found to have modestly impaired lung growth, alveolar cell proliferation and total body weight [76]. A whole-body exposure to cigarette smoke or ECIG vapour showed that nicotine-containing ECIG vapour induces addiction-related neurochemical, physiological and behavioural changes [77]. The offspring of the mice excposed to ECIG vapour showed significant behavioural alterations [78].

Systemic application of ECIG liquid in a rat model showed that e-liquid with or without nicotine leads to diminished sperm density and viability, and a decrease in testicular lactate dehydrogenase activity and 
testosterone level [79]. An identical experimental setup from the same research group revealed decreased food and energy intake and a significant decrease in cholesterol and low-density lipoprotein LDL levels [80], and alterations of the anti-oxidant defence and minor changes in renal function parameters [81]. Cardiac development was studied in zebrafish (Danio rerio) and in human embryonic stem cells (hESCs), and showed that ECIGs have a less detrimental effect in these outcomes as compared to conventional cigarettes [82]. Larva of Caenorhabditis elegans worms were exposed to ECIG liquids and this study showed that propylene glycol exposure is sufficient to induce an oxidative stress response in nematodes, while nicotine is not. Both propylene glycol and nicotine independently influence physiological measures of health and viability [83].

\section{Conclusion}

An increasing number of studies have used cell culture and animal models to investigate the effects of ECIGs. Most of these studies revealed adverse effects of ECIGs, although these were less pronounced than with TCIGs. ECIGs were found to affect cell viability in some but not all studies, but also in the absence of cytotoxic effects changes in oxidative stress, inflammatory mediator production and host defence against infection were noted. These studies focused on acute and subacute effects of ECIGs, and cell culture experiments cannot be used to show long-term effects. Notably, nicotine and flavouring agents present in ECIG products are thought to contribute to their toxic effects. Caution is needed in extrapolating ECIG studies performed in cell culture or animals to human exposures. Aerosol exposure studies in cell culture and animals are technically difficult, and therefore some researchers used extracts of vapours. Other researchers focused on e-liquids, which reflects a different exposure than inhalation of ECIG vapour. Whereas these in vitro and in vivo exposure studies raise concern regarding the use of ECIGs, conclusive answers will only be obtained with carefully conducted long-term studies in ECIG users.

\section{Ingredients and health effects}

ECIGs include a wide variety of battery-powered devices that heat a liquid, usually containing nicotine, to generate a vapour/aerosol that is inhaled [84]. Devices vary considerably in design, including the size of the device, battery power and characteristics of the liquid chamber, composition of the coil and of the wick. As discussed below, different devices can generate very different chemical exposures, and most likely different levels of toxicity.

\section{Constituents}

E-liquid

The liquid (e-liquid) is generally comprised of propylene glycol and/or vegetable glycerine, nicotine and flavourings. The concentrations of nicotine may vary widely, but are typically $3-50 \mathrm{mg} \cdot \mathrm{mL}^{-1}$, and some e-liquids are nicotine-free. The stated nicotine concentrations are not always accurate [85, 86]. A recent study of 27 US e-liquids with nominal nicotine concentrations of $6-22 \mathrm{mg} \cdot \mathrm{mL}^{-1}$ found that actual concentrations were $45-131 \%$ of the stated concentration, and that $67 \%$ had $>10 \%$ variance from stated values [86]. In most cases the measured concentrations are lower than those stated. Nicotine in e-liquids is extracted from tobacco, so the liquid may contain low levels of minor tobacco alkaloids and tobacco-specific nitrosamines (nicotine-derived nitrosamine ketone, N-nitrosonornicotine), depending on the degree of purification [85]. The ratio of propylene glycol to vegetable glycerine differs between e-liquids, with many containing more propylene glycol than vegetable glycerine. Thousands of different e-liquid flavourings are available. Flavourings consist of complex mixtures of chemicals, and may include aldehydes (such as benzaldehyde in fruit flavours and cinnamaldehyde in cinnamon flavours), diacetyl, acetyl propionyl and acetoin (butter flavours) and alcohol [87-90]. The pH of e-liquids can vary widely from 6 to 9.8, depending on nicotine content (higher $\mathrm{pH}$ with higher nicotine content) and various flavourings [91].

Aerosol

When the ECIG is activated, a current is applied to the metal coils that surround the wick, which is saturated with e-liquid. The characteristics of the aerosol depend on the composition of the liquid, the heating temperature of the coil and wick, and an individual puffing pattern. ECIGs do not generate carbon monoxide or many other toxic chemicals produced by a burning cigarette. However, at high temperatures and with frequent puffing using a puffing machine, propylene glycol and vegetable glycerine undergo thermal degradation to form acetaldehyde, formaldehyde, acrolein and other potentially toxic carbonyls [92-94]. In some devices, heating of mixtures of propylene glycol, vegetable glycerine, benzoic acid and benzaldehyde generates benzene, a human carcinogen, which is present at lower levels than in cigarette smoke [95]. In addition, thermal degradation products can be derived from the flavouring agents [96]. In general, the more powerful the battery, the higher the coil temperature, the more aerosol produced and the more potentially toxic thermal degradation products formed. The levels of formed carbonyls in ECIG aerosols are usually much lower than those generated by cigarettes, but with high-voltage settings the 
concentration of carbonyls can be as high, or higher, than those produced from cigarettes. However, research on the generation of carbonyls and other thermal degradation products with high-voltage batteries and high temperatures have been conducted with smoking machines, and there is some evidence that ECIG users will rarely operate ECIG devices under these conditions due to the potentially adverse taste of the aerosol [68].

Heating of the coils and the wick, as well as solders, can release metals into the aerosol, such as nickel and chromium (from nichrome coils), cadmium, manganese, lead, silver, tin and silicates [97]. While exposure to metals can be toxic, the levels of metals in the aerosol are generally quite low and the risk of toxicity is likely low. In addition, metals in the aerosol may be released as nanoparticles [98]. Heating of the liquids generates oxidising chemicals, including reactive oxygen species. Levels of oxidants are reported to be orders of magnitude lower than those in cigarette smoke, but higher than that of air pollution [99]. However, oxidant generation has been reported for only a few products and use conditions.

The ECIG generates a vapour that rapidly condenses to an aerosol (particles suspended in a gas) when leaving the device. The particles exhibit a bimodal size distribution [98]. The larger particles appear to consist of liquid (primarily propylene glycol and vegetable glycerine), which vapourise quickly in the air or are absorbed quickly in the lung. Very fine particles (nanoparticles), thought to consist of semivolatile chemicals and possibly metals generated near the hot coil, are also generated and persist longer as particles than the larger liquid particles.

\section{Health effects}

This section discusses data from studies with health effects as the main outcome; other sections of the statement also discuss health effects of ECIGs. Only a few studies have addressed the effects of ECIGs on users, often referred to as vapers. A human study (30 smokers versus controls) showed that acute inhalation of ECIG vapour increased respiratory impedance and airway resistance, but did not immediately impact forced expiratory volume in $1 \mathrm{~s}$ (FEV1)/forced vital capacity (FVC) ratio [100]. Another study showed an acute effect of ECIGs on airway resistance, showing increasing of airway resistance in asthmatic smokers, healthy smokers and never-smokers (ECIGs with and without nicotine) [101]. A separate study with 15 smokers and 15 controls found no effect of acute ECIG exposure on lung function as determined by FEV1/FVC ratio [102]. Two studies (1-year prospective and retrospective evaluation) showed improvements in lung function and symptoms in smokers who switched to vaping [103, 104]. Of note, these studies contain small group sizes and some originate from the same research group. Authors of references $[103,104,108,109]$ reported conflicts of interest with companies involved in ECIG manufacturing.

To date, human ECIG studies have reported an acute increase in heart rate, probably secondary to the acute effects of nicotine exposure $[105,106]$. An ECG study found that acute ECIG exposure did not impair myocardial relaxation, in contrast to conventional cigarettes [107]. While ECIG use may acutely increase blood pressure, smokers with hypertension who reduced or quit smoking by ECIG use had a significant reduction in blood pressure in two small studies [108, 109].

Several studies of the acute cardiovascular effects of ECIGs have been reported. One study found that ECIG use acutely increased aortic stiffness, while another found no change in aortic stiffness [110, 111]. Endothelial unction, assessed by flow-mediated dilation, was impaired by cigarette smoking and ECIG use, with ECIG use having a smaller effect [112]. The effects may be related to effects of nicotine, oxidative stress and/or particulates. ECIG use acutely increases circulating levels of endothelial progenitor cells, which may be evidence of endothelial injury, but can also be an acute effect of nicotine [113]. However, in this study ECIG use did not increase microvesicles associated with activation of inflammation or platelet activation, which are major mechanisms of smoking-induced cardiovascular injury. Reduced heart rate variability was reported in a study of regular ECIG users [114]. While reduced heart rate variability is a predictor of future cardiovascular events, it is likely that this is a consequence of underlying disease, rather than acute changes in heart variability (reflecting sympathetic stimulation) being a determinant of future cardiovascular events. Additionally, this study reported increased levels of oxidised LDL, consistent with increased oxidative stress, but no effect on biomarkers of inflammation. Nothing is known about the long-term effects of chronic ECIG use on lung or cardiovascular function in humans.

\section{Toxicity of constituents}

\section{Nicotine}

Nicotine is an important constituent of ECIGs, and therefore evaluation of its effects is discussed separately. While most adult consumers choose e-liquids that contain nicotine, many younger users may choose nicotine-free liquids [115]. In one study, ECIGs were found to release up to $93 \mu \mathrm{g}$ of nicotine per puff, compared to $147 \mu \mathrm{g}$ per puff for a conventional cigarette [116], but this may vary significantly between ECIG devices and liquids. 
Effects of nicotine are mediated by nicotinic acetylcholine receptors (nAChRs). Nicotinic receptors have been most intensely studied with respect to psychoactive effects or in neurological diseases, yet they are also widely expressed in a variety of cell types, including immune cells, epithelial cells, endothelial cells and adipocytes and keratinocytes [117]. In the lung, nicotinic receptors are abundantly present in epithelial cells $[118,119]$. The bronchiolar epithelium expresses the $\alpha 3, \alpha 4, \alpha 5, \alpha 7, \alpha 9, \beta 2$ and $\beta 4$ subunits of nAChRs [120-122]. This expression is most intense on the apical surface [123], where exposure to nicotine mainly occurs [124]. Moreover, activation of these receptors triggers protease expression [125], mucin production [126] and smooth muscle contraction [127, 128], which mediate airway obstruction $[129,130]$. Increasing evidence indicates that the expression of these receptors, in particular $\alpha 7 \mathrm{nAChR}$, could play a pivotal role in the development of COPD [131]. The $\alpha 7 \mathrm{nAChR}$ regulates epithelial cell proliferation [132], differentiation [123] and mediates intracellular calcium ion influx [133], which activates protein kinase C (PKC) [134]. In addition, nicotine-induced $\alpha 7 \mathrm{nAChR}$ activation decreases cystic fibrosis transmembrane receptor channel activity in the airway epithelium [131], thereby increasing mucus viscosity.

\section{Consequences of nicotine inhalation}

Nicotine promotes proliferation of airway smooth muscle [135, 136] and epithelial cells [137], which may contribute to small airway remodelling in COPD. Despite these findings, few studies have directly examined the impact of nicotine inhalation alone on emphysema in the adult lung. In elastase-treated rats, cigarette smoke from high-dose nicotine-containing cigarettes does induce more emphysematous changes than smoke from low-dose nicotine cigarettes [138]. Several animal studies have demonstrated that nicotine exposure alone could induce pathogenic responses similar to those that occur in COPD. Intranasal administration of nicotine in mice resulted in impaired autophagy, enhanced oxidative stress and bronchial epithelial cell apoptosis $[61,139]$. Thus, acute exposure to nicotine in mice induced lung processes that play a central role in the development of COPD in humans [140].

As noted previously, very few studies have evaluated how chronic nicotine inhalation impacts the development of lung disease. One recent study in mice examined the effects of a 4-month exposure to a nicotine-containing ECIG aerosol in mice. The study found that mice exposed to an ECIG aerosol containing nicotine developed airway hyperresponsiveness and histological changes consistent with emphysema, while mice exposed to the same aerosol without nicotine showed no pathological changes [71]. The emphysema that resulted from this exposure was similar to that reported in cigarette smoke-exposed mice [141]. In addition, the study found that airborne exposure to nicotine impaired ion conductance and ciliary function, and increased cytokine release in normal human bronchial epithelial cells [71]. Aside from this inhalational study, it has been shown that chronic intraperitoneal injection of nicotine induced emphysematous changes in A/J mice [142]. These studies provide early evidence implicating nicotine as a potential aetiological factor in the pathogenesis of COPD. It needs to be noted that the animals in these studies received high nicotine doses that may not correspond to human exposure. Further studies are needed to establish effects of nicotine on the human lung that may be relevant for obstructive lung diseases.

Nicotine suppresses apoptosis in lung tumours through PKC activation [143]. Although it is not a carcinogen, nicotine promotes tumour proliferation [144] and chemotherapeutic resistance [145]. Some animal studies have implicated nicotine [146], but others found that nicotine had no impact on tumourigenesis [147, 148].

While animal studies suggest that nicotine may contribute to COPD and cancer, human epidemiological studies on smokeless tobacco users do not find evidence of such effects. Smokeless tobacco (snus) exposes the user to as much nicotine as cigarette smoking, but without exposing the user to toxic products of combustion and avoiding a topical exposure of the lung. In some countries like Sweden, snus use is common, especially in males. Swedish snus delivers high levels of nicotine with relatively low levels of carcinogenic nitrosamines. Swedish males have the lowest smoking prevalence and the lowest lung cancer and COPD rates of any European country [149]. Aside from pancreatic and oesophageal cancer, which are probably nitrosamine-mediated, there is no increased incidence in any other cancer compared to nontobacco users in Sweden [150]. This suggests that nicotine, at least in an oral form without inhalation, is not a major cause of cancer or COPD in people. However, a study of survival in prostate cancer patients found that both cancer-related and total mortality was higher to a small but significant extent in either exclusive smoker or exclusive snus users [151].

The level of nicotine generated by ECIGs depends on the device and amount of nicotine in the liquid. The first-generation cigarette-like devices delivered low levels of nicotine, while the more advanced devices can deliver levels similar to cigarettes [152-154]. Cotinine levels in regular vapers have been reported to be similar to those of smokers, suggesting comparable levels of nicotine exposure $[155,156]$. Of note, users of 
high battery voltage, advanced devices with low nicotine content liquids have similar cotinine levels to users of lower voltage devices with much higher nicotine content, reflecting titration of desired nicotine levels in the body [155].

The primary pharmacological effect of nicotine is sympathetic neural stimulation [157]. Such actions could contribute to acute cardiovascular events and accelerated atherosclerosis. Epidemiological studies of Swedish snus users who, as noted above, are exposed to nicotine without combustion products, find no increase in overall rate of myocardial infarction or stroke, and no evidence of accelerated atherosclerosis based on carotid intima thickness, but do find a small but significant increased mortality after myocardial infarction [158]. One study found that in the 2 years after myocardial infarction, mortality in snus users who continued to use snus was substantially higher than that of those who quit snus [159]. The presence of confounding cannot be excluded in this retrospective study. Overall, based on studies of Swedish snus users, who are exposed to high levels of nicotine without combustion products, and studies of long-term users of nicotine medications, nicotine appears to have little cardiovascular toxicity in healthy individuals, but may pose some risk in those with underlying cardiovascular disease [158-163]. It should be noted that no data exist on a direct comparison of ECIGs, conventional cigarettes and snus, and that the role of the route of exposure is unknown. Nicotine has adverse reproductive effects, including a fetal neuroteratogenicity, impaired fetal lung development and complications of pregnancy, including premature birth, low birthweight and pre-eclampsia, and possibly impaired wound healing $[164,165]$. Minor tobacco alkaloids have nicotine-like activity and tobacco-specific nitrosamines are carcinogenic. These substances may be present in ECIG vapour, but at lower levels than conventional cigarettes.

\section{Propylene glycol and vegetable glycerine}

Propylene glycol and vegetable glycerine are common food additives, and propylene glycol has been used as a diluent in parenteral medications and in some medicinal inhalers. propylene glycol is also used to produce fog in theatrical productions and in that context has been reported to produce respiratory irritation [166]. Animal studies of the inhalational toxicity of propylene glycol have reported relatively few adverse effects [167]. As noted previously, temperature-dependent thermal degradation of propylene glycol and vegetable glycerine results in formation of potentially toxic aldehydes including acetaldehyde, formaldehyde and acrolein. Such aldehydes in adequate concentration can be irritants, can be carcinogenic and can contribute to cardiovascular and pulmonary toxicity [168, 169]. Generally, concentrations of these aldehydes n ECIG aerosol are much lower than those in cigarette smoke, but can be quite high under conditions of high heating coil temperature devices or during "dry puffing", i.e. when the liquid overheats and the wick dries out. Whether users will actually use devices that generate high levels of aldehydes, including "dry puffs", has been questioned because the resultant aerosol is harsh and unpleasant tasting. Human exposure studies of urine metabolites of acrolein, a thermal degradation product of propylene glycol and vegetable glycerine, find levels much lower than those of smokers and similar to those of nonsmokers, suggesting that actual exposure levels are low [170-173].

\section{Oxidising chemicals}

Oxidising chemicals can damage cell membranes, produce endothelial dysfunction and inflammation, promote atherogenesis and activate thrombogenesis. Oxidising chemicals are thought to be the major contributors to cardiovascular disease in smokers $[174,175]$. Reported levels of oxidants in ECIG aerosol are much lower than those generated by cigarettes [99]. However as noted previously, relatively few different ECIG devices have been tested, so the range of exposure levels is unknown.

\section{Particles and metals}

Particle exposure from cigarettes and from air pollution is associated with increased incidence of cardiovascular disease [176]. Particles have irritant and oxidant effects as described earlier, and can affect cardiac autonomic function. However, the composition of ECIG particles is quite different from that of particles generated by combustion of organic materials. The latter are much more complex and include solid carbonaceous materials. Nanoparticles are of concern because they are more persistent, and some nanoparticles are known to cross capillaries in the lung and enter the systemic circulation. The hazards posed by nanoparticles generated by ECIGs are unknown at this time.

Metals are released from heating coils and possibly from other components of the device $[97,177,178]$. Metals such as cadmium, nickel and chromium in high concentrations are carcinogenic and can cause cardiovascular and/or pulmonary disease. Levels of metals in ECIG aerosols are typically lower than those from cigarettes. Larger metal particles have been found in some liquids, and such particles could potentially cause pulmonary toxicity [177]. The chemical composition of the vapour phase, which is probably different from that of the liquid phase, has still not been studied in depth. 


\section{Flavorants}

Several flavour constituents are of toxicological concern. Benzaldehyde and cinnamaldehyde are irritants and are cytotoxic, and are of concern in terms of chronic respiratory effects [88, 89]. Diacetyl, acetyl propionyl and acetoin have been associated with pulmonary inflammation and injury, including bronchiolitis obliterans [87, 179, 180]. Diacetyl is an example of a flavouring substance that has been approved and is safe when ingested, but has established adverse health effects upon inhalation. Diacetyl was found to be present in a substantial proportion of sweet-flavoured ECIG liquids [90], but at much lower levels than those in cigarette smoke $(>6700 \mu \mathrm{g}$ per day [181]). There is evidence that some flavouring chemicals undergo thermal degradation, which could be a source of other toxic organic chemicals [96].

Due to the large number of available flavourings, a detailed toxicological evaluation of each component is not available, leaving the health effects of many ECIG flavourings largely unknown.

\section{Human health effects}

There have been few systematic studies of the health effects of ECIG use. Health effect studies are difficult to design because most ECIG users are either past or current cigarette smokers. Short-term, experimental use of ECIGs has been shown to have acute effects on airways physiology and respiratory symptoms in COPD smokers, asthmatic smokers, "healthy" smokers and healthy never-smokers [101]. Common adverse effects include throat irritation and cough [182]. Experimental studies on the effect of ECIGs on heart rate and blood pressure are discussed in the health effects section. In vitro platelet activation has been reported after exposure to ECIG extracts, similar to effects of tobacco smoke extract [183]. However, another study examined microvesicle release in vivo after ECIG use and found no evidence of markers of activation of leukocytes (reflecting inflammation) or platelet activation [113]. In a small cross-sectional study, LDL oxidisability was increased in ECIG users when compared to nonusers, consistent with elevated oxidant stress, but there were no differences in C-reactive protein or fibrinogen levels, markers of inflammation [114]. Acute pulmonary effects include increased dynamic airway compliance, which could be a result of lung irritation. Various studies in which cigarette smokers switched to vaping exclusively or who vaped and smoked fewer cigarettes per day have reported benefits consistent with harm reduction. After switching, smokers with hypertension had lower blood pressure $[108,109]$; those with asthma and COPD had improved pulmonary function and symptoms [104, 184]; and smokers without COPD demonstrated improved pulmonary small airway flow [103]. In contrast, another study showed that acute use of ECIGs in smokers with or without asthma results in cough and decreased lung function [101]. Smokers who switched to vaping reported a reduction in upper respiratory tract infections [185], but the finding is based on an online survey of vapers and needs to be interpreted with caution. In contrast, one study has reported an association between ECIG use in adolescents and chronic bronchitis symptoms, although there was no association when controlling for smoking status [186]. One case of atrial fibrillation associated with ECIG use has been reported [187].

Nicotine in high concentrations is extremely toxic and potentially fatal. A number of cases of nicotine toxicity and some deaths in children who ingested nicotine-containing e-liquids have been reported [188]. Poison centres have received numerous calls about nicotine toxicity from e-liquids, including inhalation, dermal exposure and ingestion $[189,190]$. Cases of exploding ECIG batteries, some associated with serious burns, have been reported [191].

\section{Conclusion}

ECIG aerosol contains a number of potentially toxic chemicals. The composition and probably the toxicity of ECIG aerosols varies considerably across devices and liquids. Experimental human studies demonstrate acute cardiovascular effects consistent with stimulant effects of nicotine, but there is a lack of studies evaluating the long-term effects of ECIGs. Evidence that ECIGs use cause disease in users is lacking, but the products have not been in use long enough to observe possible chronic disease associations. Most ECIG users are former and current smokers, making causation difficult to establish. As compared to conventional cigarettes, the chemicals found in the vapour are fewer and generally in much lower concentrations. A few studies with limited numbers of participants suggest short-term harm reduction in smokers with COPD, who have completely switched to the use of ECIGs or who smoke fewer cigarettes per day. In this area, numerous publications have been published from only a few groups of authors, which might introduce the possibility of research subjectivity. Due to the lack of long-term studies, no conclusions are available on the long-term effects of switching.

\section{Second-hand exposure}

Unlike tobacco cigarettes, ECIGs do not produce side-stream emissions, and therefore bystanders are only exposed to chemicals that are exhaled by vapers into the indoor environment [192]. Most of the pollutants 
that occur in ECIG aerosols are retained in the respiratory tract of the user, but a fraction of the toxicants in exhaled vapour may also impact nonusers through second-hand exposures. Several studies have confirmed the presence of harmful substances in passive vapour during ECIG use, including nicotine [193], fine and ultrafine particles [194-197], polycyclic aromatic hydrocarbons [195, 198], metals (e.g. nickel, zinc, silver) [199], reactive oxygen species [49] and volatile organic compounds [195, 196, 200]. Soule et al. [201] recently showed that ECIG use can generate fine particles (with a $50 \%$ cut-off diameter of $2.5 \mu \mathrm{m}$ ) in high concentrations during natural use conditions in indoor environments (average mean $607.12 \mu \mathrm{g} \cdot \mathrm{m}^{-3}$ ). A study monitoring fine-particle air concentrations in homes of low-income families identified no air pollution from vaping (while conventional cigarettes, use of candles, etc. did contribute to indoor air pollution) [202]. This effect is caused by the evaporation of the liquid particles in the lung of the user and in the environment after exhalation. Depending on exposure conditions (e.g. room size, number of vapers), bystanders of ECIG users may experience irritation of the throat, nose and eyes when a number of people vape in close proximity. Nicotine analysis in oral fluids of nonusers exposed to ECIG aerosols confirmed passive uptake of nicotine during vaping activity [203], although at much lower levels than passive exposure to conventional cigarettes [204, 205]. The amount of nicotine exhaled by ECIG users into the indoor environment varies greatly and depends on the device and nicotine concentration in the e-liquid. First-generation ECIG devices deliver less nicotine than late-generation devices, whereas more advanced devices with larger liquid reservoirs and higher voltage batteries produce larger amounts of aerosol and can deliver as much nicotine as a tobacco cigarette to users in the mainstream vapour [105, $152,206]$. Currently there are no studies that analyse the nicotine exposure to bystanders during the use of third-generation devices (mods) or tank models in small indoor environments (e.g. passenger compartments of cars). Nicotine released from ECIGs can stick to various surfaces [207] and may contribute to passive exposure by subsequent desorption from surfaces to indoor air [208], but whether this could result in levels that could pose any risks is not known.

\section{Conclusion}

The harm potential of second-hand exposure to ECIG aerosols is currently not known. Potential health risks for bystanders are strongly dependent on the individual exposure conditions, such as the composition of the e-liquids used, the vaping topography of the ECIG users, the number of vapers, the dimensions of the room, the amount of ventilation, and the duration of exposure. While it is highly likely that involuntary indoor exposure to ECIG chemicals is much less hazardous than exposure to second-hand cigarette smoke, it is possible that such exposure could present a potential health risk, especially to vulnerable populations, including children, pregnant women and people with cardiovascular or respiratory impairments. More research is needed in order to allow for a solid risk assessment.

\section{ECIGs as a tool for smoking cessation}

The effects of ECIGs on smoking cessation can be examined in two different ways. One approach examines the effects of ECIGs as part of a smoking cessation treatment in which they are provided proactively by healthcare professionals. The other is to assess effects of ECIG use by smokers who purchase them as consumer products. The general view and use of ECIGs as a quitting tool varies between different countries.

\section{Effects of vaping in the treatment context}

Only three randomised studies addressed this issue [209-212], and the available evidence is much weaker than the evidence available for licensed stop-smoking medications. A Cochrane meta-analysis [213] of two trials that used early ECIG models with poor nicotine delivery but provided long-term outcomes found evidence that ECIGs help smokers quit compared with placebo ECIGs, with one trial showing the same (low) effect for ECIGs and for the nicotine patch [211]. The small number of trials, low event rates and wide confidence intervals around the estimates mean that the confidence in the result is rated "low" by GRADE (Grading of Recommendations, Assessment, Development and Evaluations) classification of the quality of evidence, but the uncertainty concerns the size rather than the direction of the effect. This is because there are $>100$ randomised trials of nicotine replacement treatments that show that a provision of an alternative source of nicotine helps smokers to quit [214]. The third randomised controlled trial only had a 2-month outcome and so was not included in the meta-analysis, but it showed a significant effect of a more advanced ECIG product [212].

Five intervention studies provided smokers with ECIGs and followed them up for $\geqslant 6$ months [209, 215218]. All reported good abstinence rates (36-40\%) or reduction of cigarette consumption (50-80\%); some in populations that are normally hard-to-reach, such as smokers not wanting to quit [217] and schizophrenic patients [209, 219]. The outcomes of this last group of studies are difficult to interpret because of the absence of control groups or small group sizes. In addition, several of these publications 
originated from the same group. A recent "pragmatic trial" applying different protocols for smoking cessation in a cohort of 6131 smokers found no significant effect of ECIGs as compared to the usual-care group [220]. At the present time, the evidence for licensed stop-smoking medications is stronger. Authors of references $[209,210,216,217,219]$ reported conflicts of interest with companies involves in ECIG manufacturing.

\section{Effects of vaping on smoking cessation on the population level}

Extrapolated data from the cross-sectional survey of EU citizens in 2015 (Eurobarometer survey data) suggest that an estimated 6.1 million people in Europe report that ECIGs helped them to stop smoking [39]. Some would have stopped anyway, with other methods or unaided, but analyses of trends in quitting outcomes and ECIG impact in England suggest a net benefit [221, 222]. The most recent Eurobarometer data show that among ex-smokers in Europe, $7 \%$ had quit with the help of licensed stop-smoking medications and $6 \%$ quit with the help of ECIGs [23]. Of note, the Eurobarometer data are a collection of surveys and often not analysed in detail. The most recent UK survey estimates (population forecast based on prevalence) that there are currently 1.5 million ex-smokers in Great Britain alone who switched completely to vaping [223]. The rise in vaping experimentation among the youth is considered alarming by some authorities [224], but in France, UK and USA where data on smoking and vaping exist, the rise in vaping has been accompanied by a decline rather than an increase in smoking prevalence, particularly among young people [225-227]. The increase in ECIG use among US adult smokers has been associated with a statistically significant increase in the smoking cessation rate at the population level [228]. Compared to smokers who did not use ECIGs, those who did use ECIGs were more likely to have tried to quit $(40.1 \%$ versus $65.1 \%)$ and more likely to have quit successfully ( $4.8 \%$ versus $8.2 \%)$. These results could have been confounded by factors such as increased education, population awareness and other traditional tobacco control factors, and ongoing monitoring is needed.

Two reports provided quit rates in smokers who used different quitting methods at their last serious quit attempt $[229,230]$. In both cases, quit rates with ECIGs were significantly higher than quit rates with other methods. This needs to be interpreted cautiously because treatments were self-selected.

Finally, several studies recruited smokers who had never tried ECIGs and smokers who did try ECIGs but continued to smoke, and reported their smoking status at a later stage. A systematic review and meta-analysis of a number of studies that have examined the association between ECIG use and smoking cessation reported that ECIG use was associated overall with a significant $28 \%$ decrease in smoking cessation in the general population [231]. Other researchers have commented that the findings may be artefactual because many of the studies excluded vapers who had successfully stopped smoking from the sample at baseline [232]. A meta-analysis on ECIGs and smoking cessation in real-world and clinical settings showed that ECIGs use is associated with significantly less quitting among smokers [231]. The results of these meta-analyses come to opposing conclusions to the more recent USA longitudinal study finding that ECIG use increases the likelihood of stopping smoking, as discussed earlier [228]. Data from a prospective US cohort (random sample of 1284 smokers) showed no increased cessation rates [233].

More data on the effectiveness of ECIGs as a quitting tool on the population level will emerge when comparisons of trends in smoking prevalence and cigarette sales in countries that allow and countries that ban ECIGs become available.

\section{Conclusion}

At a population level, a number of smokers claim to have successfully stopped smoking using ECIGs. Observational studies have obvious limitations and cannot rule out the effects of self-selection. Controlled studies are needed to compare the putative effectiveness of ECIGs to the proven effectiveness of other cessation interventions to substantiate these uncontrolled observations. In the treatment context, only a few relevant studies have been published so far. Early models of ECIGs have shown a limited yet significant long-term efficacy in two randomised controlled trials and a more advanced ECIG type showed a significant short-term effect. In contrast, another study comparing different cessation approached found no significant effect of ECIGs. The evidence is limited and further studies are needed, especially studies that compare ECIGs with licensed stop-smoking treatments.

\section{Behavioural aspects and social impacts of ECIGs}

This section deals with the evidence regarding potential consequences of ECIG use, i.e. the impact of ECIGs on the social perception of smoking and with the potential interplay of ECIG use and tobacco use. The central question with regards to the social perception of smoking was whether ECIG use in public places leads to renormalisation of tobacco smoking. Central questions concerning the interplay between ECIGs and tobacco use were 1) whether ECIG use deters smoking cessation; 2) whether and why ECIG 
users continue using conventional cigarettes (dual use), which would not necessarily be associated with reduced health risks; and 3) whether ECIGs act as a gateway to smoking initiation for youths.

\section{Effect of ECIGs on renormalisation of smoking}

Only two articles directly or indirectly investigated whether ECIGs might lead to a renormalisation of smoking. One experimental study in US-Americans studied reactions to depictions of vaping in ECIG commercials and found an increase in the urge to smoke in current cigarette smokers, and a lower intention to continue abstaining from smoking in former smokers, indicating that visual depictions of vaping might increase cigarette consumption and smoking rates [234]. A cross-sectional study in US-American adolescents reported an association between a social environment favourable to ECIG use and susceptibility to cigarette use independent of respondents' own ECIG use, suggesting that an increase in ECIG use might be followed by an increase in cigarette use in adolescents through mechanisms of social normalisation [235].

\section{Does ECIG use deter smoking cessation?}

As noted previously, a meta-analysis of a number of different types of studies has reported that ECIG use is associated with a decreased likelihood of smoking cessation [231]. However, some methodological concerns about the studies and analysis have been raised [232]. Several studies indicated that the intention to quit smoking is one of the main reasons reported by adults for initiating ECIG use [42, 236-239]. In addition, studies show that ECIG use is associated with quit intentions [36, 240] and that ECIG users are more likely to have tried unsuccessfully to quit smoking in the past [241, 242]. Indeed, those who use ECIGs to quit smoking are more likely to reduce or quit tobacco use $[36,238]$, and longer duration of ECIG use has been shown to conicide with decreases in daily consumption of cigarettes [243]. Regularity of use seems to be critical as well. Daily use is associated with increased likelihood of quitting, while intermittent use has been associated with a reduced likelihood of quitting [244, 245]. Certain use characteristics and expectancies seem to moderate behavioural changes, as one cross-sectional study found positive ECIG expectancies among users to be associated with a greater likelihood of having quit smoking [238], and one longitudinal study indicated that smokers who found ECIGs more satisfying were more likely to reduce or quit smoking [246]. Product characteristics may also be important; for example, one study found the number of flavours used to be independently associated with smoking cessation [247]. However, the interplay between smoking and ECIG use might be different among young adults, as two studies reported that ECIG use among college students appears to be motivated by enjoyment rather than by the desire to quit smoking $[248,249]$. A recent study based on representative population surveys found that ECIG use is associated with increased quit attempts and increased quitting success at a population level [228].

Does ECIG use co-occur with smoking (dual use)?

Several cross-sectional studies have investigated correlates of dual use, i.e. concomitant use of ECIG and tobacco cigarettes, reporting very different prevalences of dual use. The combination of ECIGs and cigarettes was less common than other dual tobacco product use (such as cigarettes + filtered cigars and cigarettes + waterpipe) among young US-Americans in a survey from 2010/2011 [250]. However, the PATH study found that $37.4 \%$ of adults and $43 \%$ of youths used multiple nicotine products, the most common combination being cigarettes and ECIGs [6]. Other surveys have showed comparably high prevalence of dual use, with more than half of all ECIG users concomitantly smoking cigarettes in a survey among youths in the US [251] and in a survey among youths in Poland [252]. A German study reported a dual use prevalence of $\sim 50 \%$ [253]. However, a large worldwide online survey among adults revealed dual use among roughly one-fifth of ECIG users [247], and a similar prevalence was found among adults in a US-American online survey [238]. Correlates of use were quite inconsistent. The dual users among US-youths generally had a higher prevalence of current tobacco product use and lower harm perceptions for these products [251]. The findings of the Polish study suggested that adolescent dual users are more addicted to nicotine in view of their smoking behaviour (e.g. time to first cigarette, smoking intensity) [252], a finding supported by a study from Germany, in which adult dual users had significantly higher scores in the Fagerström test for nicotine dependence [253]. The aforementioned large worldwide online survey among adult ECIG users indicated that dual use was associated with higher risk perceptions about ECIGs and less frequent ECIG use [247]. This is supported by the results of the US-American online survey, which showed dual use being associated with negative expectancies about ECIGs, such as ECIGs being addictive, physically irritating and less satisfying [238]. Dual users in another US-American study described ECIGs as less harmful and addictive, but less enjoyable than tobacco cigarettes [236]. A study of ECIG use among stable smokers showed that these dual users possess characteristics that are associated with difficulty in achieving smoking cessation [242], which is also supported by a German 
study in which dual users had lower self-efficacy for abstinence, lower quit intention and higher cravings than those using only ECIGs [253].

\section{ECIGs as a potential gateway to smoking}

Quite a few studies have investigated whether ECIG use is associated with the later use of more harmful tobacco products, such as cigarettes; most of them were conducted in the USA or the UK. Several mostly cross-sectional studies found higher susceptibility to trying cigarettes among adolescent or young adult ECIG users who had never smoked cigarettes [235, 254-258], while others found tobacco use to be a predictor of intention to use ECIGs [259, 260]. Several cross-sectional studies found an association between ECIG use and smoking [260-266]. One study suggested that ECIG use leads to tobacco smoking [261], while others indicate that tobacco use is a risk factor for ECIG use [260, 262, 263, 266]. One study did not support an association between ECIG and cigarette use [267]. In longitudinal studies, and in a meta-analysis of many of the studies, ECIG users were more likely to try cigarettes than nonusers of ECIGs [235, 256, 268-270]. A recent meta-analysis on longitudinal studies on the initial use of ECIGs and subsequent cigarette smoking found that ECIG use was associated with greater risk for subsequent cigarette smoking initiation and past 30-day cigarette smoking [271]. A meta-analysis on ECIG use and intention to cigarette smoking among never-smoking adolescents and young adults showed that previous ECIG use was associated with increased smoking intention [272]. While this might be considered as evidence supporting the gateway hypothesis, it is possible that these studies did not control sufficiently for other characteristics confounding the association, such as common liability factors influencing the susceptibility to experiment with substances, including alcohol, cannabis and other tobacco products [273]. Such an alternative explanation is supported by studies finding associations between ECIG use and use of other legal and illegal substances in general [262, 264, 265, 274], and by studies demonstrating that cigarette and ECIG users share common risk factors, such as peer smoking, parental smoking and higher sensation-seeking $[18,275,276]$.

\section{Conclusion}

Regarding the question of renormalisation of smoking through ECIGs, there is still limited evidence due to a lack of studies. No evidence was found for the view that ECIGs might deter smoking cessation, but only a few studies were available on this matter. The available studies rather suggest that smokers often use ECIGs to aid in smoking cessation, at least among adults. The inconsistency in characteristics correlated with dual use suggests that a diverse group of smokers and ECIG users is gathered in this category: those who want to quit smoking with ECIGs and for whom dual use represents a transition phase; those who fail to quit smoking completely; and those who, for a variety of reasons, do not want to switch to ECIGs completely. For the gateway hypothesis, there are not enough methodologically strong data to draw definite conclusions. While most longitudinal studies find a strong association between adolescent ECIG use and the likelihood of later cigarette smoking, their designs and methodological shortcomings do not prove a gateway effect as opposed to a common liability to substance use. Likely alternative explanations supported by the literature are that shared risk factors (such as parent smoking, peer smoking, other drug use and sensation-seeking) make these adolescents generally more inclined to experiment with substances. Furthermore, there are no data on the question on duration of cigarette smoking in those who initiated tobacco with ECIGs. To conclude, the leading questions concerning the undesirable consequences of ECIG use could not be answered unequivocally, as the evidence base thus far is still insufficient. More longitudinal and methodologically sound studies are needed to understand potential long-term behavioural impacts of ECIG use, and a continuous monitoring of the potential societal and public health effects of increasing ECIG use seems justified. Recent data show that there is sufficient evidence to conclude on ECIGs as gateway to smoking initiation in children.

\section{ECIG user perspectives}

Studies within the wider empirical literature review that contained user perspectives were identified by the work groups reviewing the literature. Of these, 16 studies [253, 277-286], incorporating views on attitudes, beliefs and motivations relating to ECIGs were reviewed using thematic content analysis. All of these studies used focus groups, questionnaires, surveys or interviews as their central methodology, with views taken from a wide range of participants, including current smokers, former smokers, ECIG ever-users and dual users, and across varied age groups, from school-aged children to adults.

\section{Benefits}

In the studies analysed, the main benefits of ECIGs versus traditional tobacco cigarettes expressed by users included being a healthier option, being a useful aid when trying to reduce or quit smoking; receiving a more positive reaction from friends and family; a lack of odour; and the added flexibility of being able use them in places where smoking is banned or unacceptable. In one retrospective survey [279], participants 
reported improvements in pre-existing respiratory symptoms (including asthma and chronic obstructive lung disease).

\section{Side-effects}

Participants in two studies $[279,287]$ revealed common side-effects such as dryness of the mouth and throat [183].

\section{Reasons for starting and stopping}

One of the main reasons for trying ECIGs described across four studies [43, 277, 287, 288] was curiosity, particularly for young adults among whom experimentation levels were higher than older users. For older users, as well as current and ex-smokers, the potential for ECIGs to help reduce or quit traditional tobacco products was one of the main reasons given in several studies [42, 43, 281-283, 285, 287, 289].

Other frequently expressed reasons for trying and using ECIGs included the attraction of the flavour options and the approval of family and friends who saw them as an improvement on traditional cigarettes. Some users also saw them as a recreational product, with young people in one study specifically viewing them as part of the ever-growing technological culture in their daily lives [284].

Three studies [42, 43, 290] explored the reasons behind users stopping using ECIGs, which included loss of interest, health concerns and the perception that they were not fashionable. According to recent 2017 Eurobarometer data, 55\% of respondents think that ECIGs are harmful to the health of their users [23].

\section{Lack of information}

In three studies [278, 284, 287], users expressed low levels of knowledge about ECIGs, including their ingredients and long-term effects. There were also some individual concerns expressed about monitoring, regulation and safety.

\section{Areas for further research}

Areas indicated in these studies for further research in the view of the users included the motivations of young people and their experimental behaviour with ECIGs; the extent to which flavours and nicotine content contribute to initiation and regular use; exploration of the social norms surrounding ECIGs; the possible role/potential as a harm-reduction or cessation tool among adult smokers; and to understand the context and nature of use among the next generation, as this may be quite different to use among current teenagers.

\section{Conclusions}

The scientific field of ECIGs is complex and grows quickly. In parallel, new products to replace conventional cigarettes and current ECIGs are being developed continually by the industry. Therefore, whereas the literature review within this statement is a snapshot of the present situation, it does highlight several important issues regarding the use of ECIGs. The main conclusions of this statement are as follows.

- The use of ECIGs has increased in the past few years in adults and adolescents. In adults and especially in adolescents, regular use of ECIGs is largely limited to current or ex-smokers.

- ECIG aerosol contains potentially toxic chemicals. There is a lack of data on their long-term effects and thus the toxicity of ECIGs remains to be determined. Therefore, at the present time it cannot be concluded that long-term use of ECIGs is safer than that of tobacco products.

- Second-hand exposure to ECIG chemicals may represent a potential risk, especially to vulnerable populations. There are a limited number of studies on second-hand exposures to ECIGs, and they do not provide sufficient evidence enough to exclude a potential risk.

- The use of ECIGs as a smoking cessation tool is insufficiently supported by controlled clinical trials. In the treatment context, only a few relevant studies of early ECIG types have been published so far. They show a small positive effect, but further studies are needed to evaluate the usefulness of current ECIG products as cessation tools. There is a lack of evidence that ECIGs are an aid to smoking cessation and there is a lack of studies that compare ECIG as smoking cessation tool to other approaches to smoking cessation.

- So far, there are not sufficient data to exclude that the use of ECIGs results in a renormalisation of smoking or for the gateway hypothesis in adults. Recent data show that there is sufficient evidence to conclude on ECIGs as gateway to smoking initiation in children.

- Experiments in cell cultures and animal studies show that ECIGs can have multiple negative effects, but fewer than conventional cigarettes or other tobacco products. One main shortcoming of the available information on ECIGs is the absence of any long-term data on active and passive exposure. By implication, it is not possible to exclude that new risks may emerge from ECIG use. 
TABLE 2 Areas of future research

Epidemiology

- Provide long-term cohort data on risk for disease development, including lung, cardiovascular and infectious disease in ECIG users

- Provide long-term data on risk for lung, cardiovascular and infectious disease in ECIG users who switched to vaping compared to those who continue to smoke

- Compare trends in cigarette sales, smoking prevalence and, later on, in disease development le.g. cancer and CVD morbidityl, in countries that allow and countries that restrict vaping

- Compare between different countries ECIG use pattern among adolescents, analysing differences in type of ECIGs that are used, risk factors for their use and long-term impact on cigarette smoking

- Studies on the gateway hypothesis and normalisation of smoking

- Studies that assess risk of ECIGs for second-hand exposures

Clinical studies - Conduct RCTs that compare the effectiveness of ECIGs with that of other stop-smoking interventions

- Conduct RCTs on combination of ECIGs with licenced therapies for smoking cessation

- Further characterisation of flavouring toxicology during exposure

- Characterisation of second-hand exposures in different settings

Basic research - Better assessment of actual exposure and deposition in models of ECIG exposure

- Long-term studies (including time-course studies) to assess effects of prolonged ECIG use

- Identification of molecular pattern to identify risks for disease development

- More detailed analysis of components and ECIG design and effects of conditions of use on generation of potentially toxic thermal degradation products

- Additional studies which characterise the health effects and toxicology of ECIG flavourings, particularly those that have not previously been studied

ECIG: electronic cigarette; CVD: cardiovascular disease; RCT: randomised controlled trial.

These conclusions are in line with the FIRS position statement on ECIGs [2] underling the fact that "health risks of electronic cigarettes have not been adequately studied" and thus "potential benefits to an individual smoker should be weighed against harm to the population of increased social acceptability of smoking and use of nicotine". The task force identified several areas for future independent research, summarised in table 2. In line with the ERS statement that "human lungs are made to breath clean air and any substance inhaled long term may be detrimental" [291] and on the basis of the literature analysis, the task force suggests a cautious use and application of ECIGs to avoid potential health problems or dangers. The area of ECIGs and novel inhaled devices remains a challenging and interesting field for healthcare providers, politicians and numerous other stakeholders. More independent and well-controlled studies are needed.

Conflict of interest: R. Bals reports grants and personal fees from AstraZeneca, Boehringer Ingelheim and Novartis, personal fees from GlaxoSmithKline, Grifols and CSL Behring, and grants from German Federal Ministry of Education and Research (BMBF), Competence Network Asthma and COPD (ASCONET), Sander Stiftung, Schwiete Stiftung, Krebshilfe and Mukoviszidose eV, outside the submitted work. J. Boyd is an employee of the ERS. S. Esposito has nothing to disclose. R. Foronjy reports travel support for meetings of the ERS task force from European Respiratory Society, during the conduct of the study. P.S. Hiemstra reports travel support for meetings of the ERS task force from European Respiratory Society, during the conduct of the study; and departmental research grants from Galapagos N.V. and Boehringer Ingelheim, outside the submitted work. C.A. Jiménez-Ruiz has nothing to disclose. P. Katsaounou reports honoria, travel support and grants from GSK, Pfizer, Menarini, Chiesi and BI, outside the submitted work. A. Lindberg reports personal fees for advisory board work, lecturing at sponsored meetings, and writing part of an information brochure on COPD (epidemiology, comorbidity) from AstraZeneca, personal fees for advisory board work, lecturing at sponsored meetings, and participating on a scientific advisory board for a scietific symposium from Boehringer Ingelheim, and personal fees for lecturing at sponsored meetings from Novartis and Active Care, outside the submitted work. C. Metz has nothing to disclose. W. Schober has nothing to disclose. A. Spira reports personal fees for consultancy from Veracyte Inc, and personal fees for consultancy and employment from Johnson and Johnson, outside the submitted work. F. Blasi reports grants and personal fees from AstraZeneca, Bayer, Grifols and Pfizer, personal fees from Chiesi, GSK, Guidotti, Menarini, Novartis, Teva and Zambon, and grants from Insmed, outside the submitted work.

Support statement: This work was supported by the European Respiratory Society. Funding information for this article has been deposited with the Crossref Funder Registry.

\section{References}

1 Zyoud S, Al-Jabi SW, Sweileh WM. Worldwide research productivity in the field of electronic cigarette: a bibliometric analysis. BMC Public Health 2014; 14: 667.

2 Schraufnagel DE, Blasi F, Drummond MB, et al. Electronic cigarettes. A position statement of the forum of international respiratory societies. Am J Respir Crit Care Med 2014; 190: 611-618.

3 Camenga DR, Delmerico J, Kong G, et al. Trends in use of electronic nicotine delivery systems by adolescents. Addict Behav 2014; 39: 338-340.

4 Cho JH, Shin E, Moon S-S. Electronic-cigarette smoking experience among adolescents. J Adolesc Health 2011; 49: 542-546. 
Barnett TE, Soule EK, Forrest JR, et al. Adolescent electronic cigarette use: associations with conventional cigarette and hookah smoking. Am J Prev Med 2015; 49: 199-206.

6 Kasza KA, Ambrose BK, Conway KP, et al. Tobacco-product use by adults and youths in the United States in 2013 and 2014. N Engl J Med 2017; 376: 342-353.

7 White J, Li J, Newcombe R, et al. Tripling use of electronic cigarettes among New Zealand adolescents between 2012 and 2014. I Adolesc Health 2015; 56: 522-528.

8 Caraballo RS, Jamal A, Nguyen KH, et al. Electronic nicotine delivery system use among U.S. adults, 2014. Am J Prev Med 2016; 50: 226-229.

9 Czoli CD, Hammond D, Reid JL, et al. Use of conventional and alternative tobacco and nicotine products among a sample of Canadian youth. J Adolesc Health 2015; 57: 123-125.

10 Dutra LM, Glantz SA. Electronic cigarettes and conventional cigarette use among U.S. adolescents: a cross-sectional study. JAMA Pediatr 2014; 168: 610-617.

11 Eastwood B, Dockrell MJ, Arnott D, et al. Electronic cigarette use in young people in Great Britain 2013-2014. Public Health 2015; 129: 1150-1156.

12 Gilreath TD, Leventhal A, Barrington-Trimis JL, et al. Patterns of alternative tobacco product use: emergence of hookah and e-cigarettes as preferred products amongst youth. J Adolesc Health 2016; 58: 181-185.

13 Krishnan-Sarin S, Morean ME, Camenga DR, et al. E-cigarette use among high school and middle school adolescents in Connecticut. Nicotine Tob Res 2015; 17: 810-818.

14 Lee YO, Hebert CJ, Nonnemaker JM, et al. Youth tobacco product use in the United States. Pediatrics 2015; 135: 409-415.

15 Corsi DJ, Lippert AM. An examination of the shift in school-level clustering of US adolescent electronic cigarette use and its multilevel correlates, 2011-2013. Health Place 2016; 38: 30-38.

16 Warner KE. Frequency of e-cigarette use and cigarette smoking by American students in 2014. Am J Prev Med 2016; 51: 179-184.

17 Cardenas VM, Breen PJ, Compadre CM, et al. The smoking habits of the family influence the uptake of e-cigarettes in US children. Ann Epidemiol 2015; 25: 60-62.

18 Hanewinkel R, Isensee B. Risk factors for e-cigarette, conventional cigarette, and dual use in German adolescents: a cohort study. Prev Med 2015; 74: 59-62.

19 Bauld L, MacKintosh AM, Ford A, et al. E-cigarette uptake amongst UK youth: experimentation, but little or no regular use in nonsmokers. Nicotine Tob Res 2016; 18: 102-103.

20 Ooms GI, Bosdriesz JR, Portrait FR, et al. Sociodemographic differences in the use of electronic nicotine delivery systems in the European Union. Nicotine Tob Res 2016; 18: 724-729.

21 Vardavas CI, Filippidis FT, Agaku IT. Determinants and prevalence of e-cigarette use throughout the European Union: a secondary analysis of 26566 youth and adults from 27 countries. Tob Control 2015; 24: 442-448.

22 Agaku IT, Filippidis FT, Vardavas CI, et al. Poly-tobacco use among adults in 44 countries during 2008-2012: evidence for an integrative and comprehensive approach in tobacco control. Drug Alcohol Depend 2014; 139: 60-70.

23 European Commission. Special Eurobarometer 458: Attitudes of Europeans Towards Tobacco and Electronic Cigarettes. 2017. https://data.europa.eu/euodp/en/data/dataset/S2146_87_1_458_ENG Date last updated: May 25, 2018.

24 Tavolacci MP, Vasiliu A, Romo L, et al. Patterns of electronic cigarette use in current and ever users among college students in France: a cross-sectional study. BMJ Open 2016; 6: e011344.

25 Gravely S, Fong GT, Cummings KM, et al. Awareness, trial, and current use of electronic cigarettes in 10 countries: findings from the ITC project. Int J Environ Res Public Health 2014; 11: 11691-11704.

26 Andler R, Guignard R, Wilquin JL, et al. Electronic cigarette use in France in 2014. Int J Public Health 2016; 61: 159-165.

27 Babineau K, Taylor K, Clancy L. Electronic cigarette use among Irish youth: a cross sectional study of prevalence and associated factors. PLoS One 2015; 10: e0126419.

28 Adkison SE, O'Connor RJ, Bansal-Travers M, et al. Electronic nicotine delivery systems: international tobacco control four-country survey. Am J Prev Med 2013; 44: 207-215.

29 Allem J-P, Forster M, Neiberger A, et al. Characteristics of emerging adulthood and e-cigarette use: findings from a pilot study. Addict Behav 2015; 50: 40-44

30 Brown J, West R, Beard E, et al. Prevalence and characteristics of e-cigarette users in Great Britain: findings from a general population survey of smokers. Addict Behav 2014; 39: 1120-1125.

31 Dockrell M, Morrison R, Bauld L, et al. E-cigarettes: prevalence and attitudes in Great Britain. Nicotine Tob Res 2013; 15: 1737-1744.

32 Douptcheva N, Gmel G, Studer J, et al. Use of electronic cigarettes among young Swiss men. J Epidemiol Community Health 2013; 67: 1075-1076.

33 King BA, Patel R, Nguyen KH, et al. Trends in awareness and use of electronic cigarettes among US adults, 2010-2013. 2015; 17: 219-227.

34 McMillen RC, Gottlieb MA, Shaefer RMW, et al. Trends in electronic cigarette use among U.S. adults: use is increasing in both smokers and nonsmokers. Nicotine Tob Res 2015; 17: 1195-1202.

35 Weaver SR, Majeed BA, Pechacek TF, et al. Use of electronic nicotine delivery systems and other tobacco products among USA adults, 2014: results from a national survey. Int J Public Health 2016; 61: 177-188.

36 Rutten LJF, Blake KD, Agunwamba AA, et al. Use of e-cigarettes among current smokers: associations among reasons for use, quit intentions, and current tobacco use. Nicotine Tob Res 2015; 17: 1228-1234.

37 Adkison SE, O'Connor RJ, Bansal-Travers M, et al. Electronic nicotine delivery systems: international tobacco control four-country survey. Am J Prev Med 2013; 44: 207-215.

38 Borderud SP, Li Y, Burkhalter JE, et al. Electronic cigarette use among patients with cancer: characteristics of electronic cigarette users and their smoking cessation outcomes. Cancer 2014; 120: 3527-3535.

39 Farsalinos KE, Poulas K, Voudris V, et al. Electronic cigarette use in the European Union: analysis of a representative sample of 27460 Europeans from 28 countries. Addiction 2016; 111: 2032-2040.

40 Filippidis FT, Gerovasili V, Laverty AA. Commentary on Farsalinos et al. (2016): Electronic cigarette use in the European Union: analysis of a representative sample of 27460 Europeans from 28 countries. Addiction 2017; 112: 544-545. 
41 Laverty AA, Vardavas CI, Filippidis FT. Design and marketing features influencing choice of e-cigarettes and tobacco in the EU. Eur J Public Health 2016; 26: 838-841.

42 Pepper JK, Ribisl KM, Emery SL, et al. Reasons for starting and stopping electronic cigarette use. Int J Environ Res Public Health 2014; 11: 10345-10361.

43 Kong G, Morean ME, Cavallo DA, et al. Reasons for electronic cigarette experimentation and discontinuation among adolescents and young adults. Nicotine Tob Res 2015; 17: 847-854.

44 Cummins SE, Zhu SH, Tedeschi GJ, et al. Use of e-cigarettes by individuals with mental health conditions. Tob Control 2014; 23: Suppl. 3, iii48-iii53.

45 Prochaska JJ, Grana RA. E-cigarette use among smokers with serious mental illness. PLoS One 2014; 9: e113013.

46 Lee YO, Hebert CJ, Nonnemaker JM, et al. Multiple tobacco product use among adults in the United States: cigarettes, cigars, electronic cigarettes, hookah, smokeless tobacco, and snus. Prev Med 2014; 62: 14-19.

47 Amato MS, Boyle RG, Levy D. How to define e-cigarette prevalence? Finding clues in the use frequency distribution. Tob Control 2016; 25: e24-e29.

48 Giovenco DP, Lewis MJ, Delnevo CD. Factors associated with e-cigarette use: a national population survey of current and former smokers. Am J Prev Med 2014; 47: 476-480.

49 Lerner CA, Sundar IK, Yao H, et al. Vapors produced by electronic cigarettes and e-juices with flavorings induce toxicity, oxidative stress, and inflammatory response in lung epithelial cells and in mouse lung. PLoS One 2015; 10: e0116732.

50 Hiemstra PS, Bals R. Basic science of electronic cigarettes: assessment in cell culture and in vivo models. Respir Res 2016; 17: 127.

51 Schweitzer KS, Chen SX, Law S, et al. Endothelial disruptive proinflammatory effects of nicotine and e-cigarette vapor exposures. Am J Physiol Lung Cell Mol Physiol 2015; 309: L175-L187.

52 Farsalinos KE, Romagna G, Allifranchini E, et al. Comparison of the cytotoxic potential of cigarette smoke and electronic cigarette vapour extract on cultured myocardial cells. Int J Environ Res Public Health 2013; 10: 5146-5162.

53 Romagna G, Allifranchini E, Bocchietto E, et al. Cytotoxicity evaluation of electronic cigarette vapor extract on cultured mammalian fibroblasts (ClearStream-LIFE): comparison with tobacco cigarette smoke extract. Inhal Toxicol 2013; 25: 354-361.

54 Moses E, Wang T, Corbett S, et al. Molecular impact of electronic cigarette aerosol exposure in human bronchial epithelium. Toxicol Sci 2017; 155: 248-257.

55 Misra M, Leverette RD, Cooper BT, et al. Comparative in vitro toxicity profile of electronic and tobacco cigarettes, smokeless tobacco and nicotine replacement therapy products: e-liquids, extracts and collected aerosols. Int J Environ Res Public Health 2014; 11: 11325-11347.

56 Scheffler S, Dieken $\mathrm{H}$, Krischenowski $\mathrm{O}$, et al. Evaluation of E-cigarette liquid vapor and mainstream cigarette smoke after direct exposure of primary human bronchial epithelial cells. Int J Environ Res Public Health 2015; 12: 3915-3925.

57 Cervellati F, Muresan XM, Sticozzi C, et al. Comparative effects between electronic and cigarette smoke in human keratinocytes and epithelial lung cells. Toxicol In Vitro 2014; 28: 999-1005.

58 Husari A, Shihadeh A, Talih S, et al. Acute exposure to electronic and combustible cigarette aerosols: effects in an animal model and in human alveolar cells. Nicotine Tob Res 2016; 18: 613-619.

59 Aug A, Altraja S, Kilk K, et al. E-cigarette affects the metabolome of primary normal human bronchial epithelial cells. PLoS One 2015; 10: e0142053.

60 Neilson L, Mankus C, Thorne D, et al. Development of an in vitro cytotoxicity model for aerosol exposure using 3D reconstructed human airway tissue; application for assessment of e-cigarette aerosol. Toxicol In Vitro 2015; 29: 1952-1962.

61 Shivalingappa PC, Hole R, Westphal CV, et al. Airway exposure to e-cigarette vapors impairs autophagy and induces aggresome formation. Antioxid Redox Signal 2015; 24: doi: 10.1089/ars.2015.6367.

62 Sancilio S, Gallorini M, Cataldi A, et al. Cytotoxicity and apoptosis induction by e-cigarette fluids in human gingival fibroblasts. Clin Oral Investig 2016; 20: 477-483.

63 Yoshiyama S, Chen Z, Okagaki T, et al. Nicotine exposure alters human vascular smooth muscle cell phenotype from a contractile to a synthetic type. Atherosclerosis 2014; 237: 464-470.

64 Bahl V, Lin S, Xu N, et al. Comparison of electronic cigarette refill fluid cytotoxicity using embryonic and adult models. Reprod Toxicol 2012; 34: 529-537.

65 Higham A, Rattray NJ, Dewhurst JA, et al. Electronic cigarette exposure triggers neutrophil inflammatory responses. Respir Res 2016; 17: 56.

66 Rubenstein DA, Hom S, Ghebrehiwet B, et al. Tobacco and e-cigarette products initiate Kupffer cell inflammatory responses. Mol Immunol 2015; 67: 652-660.

$67 \mathrm{Wu} \mathrm{Q}$, Jiang D, Minor $\mathrm{M}$, et al. Electronic cigarette liquid increases inflammation and virus infection in primary human airway epithelial cells. PLoS One 2014; 9: e108342.

68 Kosmider L, Sobczak A, Fik M, et al. Carbonyl compounds in electronic cigarette vapors: effects of nicotine solvent and battery output voltage. Nicotine Tob Res 2014; 16: 1319-1326.

$69 \mathrm{Yu} \mathrm{V}$, Rahimy M, Korrapati A, et al. Electronic cigarettes induce DNA strand breaks and cell death independently of nicotine in cell lines. Oral Oncol 2016; 52: 58-65.

70 Lim HB, Kim SH. Inhallation of e-cigarette cartridge solution aggravates allergen-induced airway inflammation and hyper-responsiveness in mice. Toxicol Res 2014; 30: 13-18.

71 Garcia-Arcos I, Geraghty P, Baumlin N, et al. Chronic electronic cigarette exposure in mice induces features of COPD in a nicotine-dependent manner. Thorax 2016; 71: 1119-1129.

72 Phillips B, Veljkovic E, Peck MJ, et al. A 7-month cigarette smoke inhalation study in C57BL/6 mice demonstrates reduced lung inflammation and emphysema following smoking cessation or aerosol exposure from a prototypic modified risk tobacco product. Food Chem Toxicol 2015; 80: 328-345.

73 Sussan TE, Gajghate S, Thimmulappa RK, et al. Exposure to electronic cigarettes impairs pulmonary anti-bacterial and anti-viral defenses in a mouse model. PLoS One 2015; 10: e0116861.

74 Hwang $\mathrm{JH}$, Lyes $\mathrm{M}$, Sladewski $\mathrm{K}$, et al. Electronic cigarette inhalation alters innate immunity and airway cytokines while increasing the virulence of colonizing bacteria. J Mol Med 2016; 94: 667-679.

75 Canistro D, Vivarelli F, Cirillo S, et al. E-cigarettes induce toxicological effects that can raise the cancer risk. Sci Rep 2017; 7: 2028. 
McGrath-Morrow SA, Hayashi M, Aherrera A, et al. The effects of electronic cigarette emissions on systemic cotinine levels, weight and postnatal lung growth in neonatal mice. PLoS One 2015; 10: e0118344.

Ponzoni L, Moretti M, Sala M, et al. Different physiological and behavioural effects of e-cigarette vapour and cigarette smoke in mice. Eur Neuropsychopharmacol 2015; 25: 1775-1786.

Smith D, Aherrera A, Lopez A, et al. Adult behavior in male mice exposed to e-cigarette nicotine vapors during late prenatal and early postnatal life. PLoS One 2015; 10: e0137953.

Golli NE, Rahali D, Jrad-Lamine A, et al. Impact of electronic-cigarette refill liquid on rat testis. Toxicol Mech Methods 2016; 26: 427-434.

Golli NE, Dkhili H, Dallagi Y, et al. Comparison between electronic cigarette refill liquid and nicotine on metabolic parameters in rats. Life Sci 2016; 146: 131-138.

Golli NE, Jrad-Lamine A, Neffati H, et al. Impact of e-cigarette refill liquid exposure on rat kidney. Regul Toxico Pharmacol 2016; 77: 109-116.

Palpant NJ, Hofsteen P, Pabon L, et al. Cardiac development in zebrafish and human embryonic stem cells is inhibited by exposure to tobacco cigarettes and e-cigarettes. PLoS One 2015; 10: e0126259.

Panitz D, Swamy H, Nehrke K. A C. elegans model of electronic cigarette use: physiological effects of e-liquids in nematodes. BMC Pharmacol Toxicol 2015; 16: 32.

Brown JE, Luo W, Isabelle LM, et al. Candy flavorings in tobacco. N Engl J Med 2014; 370: 2250-2252.

Lisko JG, Tran H, Stanfill SB, et al. Chemical composition and evaluation of nicotine, tobacco alkaloids, pH, and selected flavors in e-cigarette cartridges and refill solutions. Nicotine Tob Res 2015; 17: 1270-1278.

Peace MR, Baird TR, Smith N, et al. Concentration of nicotine and glycols in 27 electronic cigarette formulations. J Anal Toxicol 2016; 40: 403-407.

Barrington-Trimis JL, Samet JM, McConnell R. Flavorings in electronic cigarettes: an unrecognized respiratory health hazard? JAMA 2014; 312: 2493-2494.

Behar RZ, Davis B, Wang Y, et al. Identification of toxicants in cinnamon-flavored electronic cigarette refil fluids. Toxicol In Vitro 2014; 28: 198-208.

Kosmider L, Sobczak A, Prokopowicz A, et al. Cherry-flavoured electronic cigarettes expose users to the inhalation irritant, benzaldehyde. Thorax 2016; 71: 376-377.

Farsalinos KE, Kistler KA, Gillman G, et al. Evaluation of electronic cigarette liquids and aerosol for the presence of selected inhalation toxins. Nicotine Tob Res 2015; 17: 168-174.

El-Hellani A, El-Hage R, Baalbaki R, et al. Free-base and protonated nicotine in electronic cigarette liquids and aerosols. Chem Res Toxicol 2015; 28: 1532-1537.

Jensen RP, Luo W, Pankow JF, et al. Hidden formaldehyde in e-cigarette aerosols. $N$ Engl J Med 2015; 372: 392-394.

Sleiman M, Logue JM, Montesinos VN, et al. Emissions from electronic cigarettes: key parameters affecting the release of harmful chemicals. Environ Sci Technol 2016; 50: 9644-9651.

Uchiyama S, Ohta K, Inaba Y, et al. Determination of carbonyl compounds generated from the e-cigarette using coupled silica cartridges impregnated with hydroquinone and 2,4-dinitrophenylhydrazine, followed by high-performance liquid chromatography. Anal Sci 2013; 29: 1219-1222.

Pankow JF, Kim K, McWhirter KJ, et al. Benzene formation in electronic cigarettes. PLoS One 2017; 12: e0173055. Khlystov A, Samburova V. Flavoring compounds dominate toxic aldehyde production during e-cigarette vaping. Environ Sci Technol 2016; 50: 13080-13085.

Goniewicz ML, Knysak J, Gawron M, et al. Levels of selected carcinogens and toxicants in vapour from electronic cigarettes. Tob Control 2014; 23: 133-139.

Mikheev VB, Brinkman MC, Granville CA, et al. Real-time measurement of electronic cigarette aerosol size distribution and metals content analysis. Nicotine Tob Res 2016; 18: 1895-1902.

Goel R, Durand E, Trushin N, et al. Highly reactive free radicals in electronic cigarette aerosols. Chem Res Toxicol 2015; 28: 1675-1677.

Vardavas CI, Anagnostopoulos N, Kougias M, et al. Short-term pulmonary effects of using an electronic cigarette: impact on respiratory flow resistance, impedance, and exhaled nitric oxide. Chest 2012; 141: 1400-1406. Palamidas A, Tsikrika S, Katsaounou P, et al. Acute effects of short term use of e-cigarettes on airways physiology and respiratory symptoms in smokers with and without airways obstructive diseases and in healthy non smokers. Tob Prev Cessation 2017; 3: 5.

Flouris AD, Chorti MS, Poulianiti KP, et al. Acute impact of active and passive electronic cigarette smoking on serum cotinine and lung function. Inhal Toxicol 2013; 25: 91-101.

cessation trial of electronic cigarettes. Clin Sci 2016; 130: 1929-1937.

Polosa R, Morjaria JB, Caponnetto P, et al. Evidence for harm reduction in COPD smokers who switch to electronic cigarettes. Respir Res 2016; 17: 166.

5 Vansickel AR, Cobb CO, Weaver MF, et al. A clinical laboratory model for evaluating the acute effects of electronic "cigarettes": nicotine delivery profile and cardiovascular and subjective effects. Cancer Epidemiol Biomarkers Prev 2010; 19: 1945-1953.

Vansickel AR, Eissenberg T. Electronic cigarettes: effective nicotine delivery after acute administration. Nicotine Tob Res 2013; 15: 267-270.

Farsalinos KE, Tsiapras D, Kyrzopoulos S, et al. Acute effects of using an electronic nicotine-delivery device (electronic cigarette) on myocardial function: comparison with the effects of regular cigarettes. BMC Cardiovasc Disord 2014; 14: 78.

08 Polosa R, Morjaria JB, Caponnetto P, et al. Blood pressure control in smokers with arterial hypertension who switched to electronic cigarettes. Int J Environ Res Public Health 2016; 13: E1123.

Farsalinos K, Cibella F, Caponnetto P, et al. Effect of continuous smoking reduction and abstinence on blood pressure and heart rate in smokers switching to electronic cigarettes. Intern Emerg Med 2016: 85-94.

Vlachopoulos C, Ioakeimidis N, Abdelrasoul M, et al. Electronic cigarette smoking increases aortic stiffness and blood pressure in young smokers. J Am Coll Cardiol 2016; 67: 2802-2803.

Szołtysek-Bołdys I, Sobczak A, Zielińska-Danch W, et al. Influence of inhaled nicotine source on arterial stiffness. Przegl Lek 2014; 71: 572-575. 
112 Carnevale R, Sciarretta S, Violi F, et al. Acute impact of tobacco vs electronic cigarette smoking on oxidative stress and vascular function. Chest 2016; 150: 606-612.

113 Antoniewicz L, Bosson JA, Kuhl J, et al. Electronic cigarettes increase endothelial progenitor cells in the blood of healthy volunteers. Atherosclerosis 2016; 255: 179-185.

114 Moheimani RS, Bhetraratana M, Yin F, et al. Increased cardiac sympathetic activity and oxidative stress in habitual electronic cigarette users: implications for cardiovascular risk. JAMA Cardiol 2017; 2: 278-284.

115 Miech RA, O'Malley PM, Johnston LD, et al. E-cigarettes and the drug use patterns of adolescents. Nicotine Tob Res 2016; 18: 654-659.

116 Laugesen M. Nicotine and toxicant yield ratings of electronic cigarette brands in New Zealand. NZ Med J 2015; 128: $77-82$

117 Filippini P, Cesario A, Fini M, et al. The yin and yang of non-neuronal $\alpha 7$-nicotinic receptors in inflammation and autoimmunity. Curr Drug Targets 2012; 13: 644-655.

118 Jiang Y, Dai A, Zhou Y, et al. Nicotine elevated intracellular $\mathrm{Ca}^{2+}$ in rat airway smooth muscle cells via activating and up-regulating $\alpha 7$-nicotinic acetylcholine receptor. Cell Physiol Biochem 2014; 33: 389-401.

119 Wilk JB, Shrine NR, Loehr LR, et al. Genome-wide association studies identify CHRNA5/3 and HTR4 in the development of airflow obstruction. Am J Respir Crit Care Med 2012; 186: 622-632.

120 Zia S, Ndoye A, Nguyen VT, et al. Nicotine enhances expression of the alpha 3, alpha 4, alpha 5, and alpha 7 nicotinic receptors modulating calcium metabolism and regulating adhesion and motility of respiratory epithelial cells. Res Commun Mol Pathol Pharmacol 1997; 97: 243-262.

121 Maus AD, Pereira EF, Karachunski PI, et al. Human and rodent bronchial epithelial cells express functional nicotinic acetylcholine receptors. Mol Pharmacol 1998; 54: 779-788.

122 Carlisle DL, Hopkins TM, Gaither-Davis A, et al. Nicotine signals through muscle-type and neuronal nicotinic acetylcholine receptors in both human bronchial epithelial cells and airway fibroblasts. Respir Res 2004; 5: 27.

123 Maouche K, Polette M, Jolly T, et al. $\alpha 7$ nicotinic acetylcholine receptor regulates airway epithelium differentiation by controlling basal cell proliferation. Am J Pathol 2009; 175: 1868-1882.

124 Proskocil BJ, Sekhon HS, Jia Y, et al. Acetylcholine is an autocrine or paracrine hormone synthesized and secreted by airway bronchial epithelial cells. Endocrinology 2004; 145: 2498-2506.

125 Li ZZ, Dai QY. Pathogenesis of abdominal aortic aneurysms: role of nicotine and nicotinic acetylcholine receptors. Mediators Inflamm 2012; 2012: 103120.

$126 \mathrm{Fu} \mathrm{XW}$, Wood K, Spindel ER. Prenatal nicotine exposure increases GABA signaling and mucin expression in airway epithelium. Am J Respir Cell Mol Biol 2011; 44: 222-229.

127 Hahn HL, Lang M, Bleicher S, et al. Nicotine-induced airway smooth muscle contraction: neural mechanisms involving the airway epithelium. Functional and histologic studies in vitro. Clin Investig 1992; 70: 252-262.

128 Takayanagi I, Kizawa Y, Sone H. Action of nicotine on guinea-pig isolated bronchial smooth muscle preparation. Gen Pharmacol 1984; 15: 349-352.

129 Boucherat O, Boczkowski J, Jeannotte L, et al. Cellular and molecular mechanisms of goblet cell metaplasia in the respiratory airways. Exp Lung Res 2013; 39: 207-216.

130 Barnes PJ. Cellular and molecular mechanisms of chronic obstructive pulmonary disease. Clin Chest Med 2014; 35: 71-86.

131 Maouche K, Medjber K, Zahm JM, et al. Contribution of $\alpha 7$ nicotinic receptor to airway epithelium dysfunction under nicotine exposure. Proc Natl Acad Sci USA 2013; 110: 4099-4104.

132 Medjber K, Freidja ML, Grelet S, et al. Role of nicotinic acetylcholine receptors in cell proliferation and tumour invasion in broncho-pulmonary carcinomas. Lung Cancer 2015; 87: 258-264.

133 Séguéla P, Wadiche J, Dineley-Miller K, et al. Molecular cloning, functional properties, and distribution of rat brain alpha 7: a nicotinic cation channel highly permeable to calcium. J Neurosci 1993; 13: 596-604.

134 Boncoeur E, Bouvet GF, Migneault F, et al. Induction of nitric oxide synthase expression by lipopolysaccharide is mediated by calcium-dependent PKC $\alpha-\beta 1$ in alveolar epithelial cells. Am J Physiol Lung Cell Mol Physiol 2013; 305: L175-L184.

$135 \mathrm{He}$ F, Li B, Zhao Z, et al. The pro-proliferative effects of nicotine and its underlying mechanism on rat airway smooth muscle cells. PLoS One 2014; 9: e93508.

136 Pera T, Gosens R, Lesterhuis AH, et al. Cigarette smoke and lipopolysaccharide induce a proliferative airway smooth muscle phenotype. Respir Res 2010; 11: 48.

137 Grozio A, Catassi A, Cavalieri Z, et al. Nicotine, lung and cancer. Anticancer Agents Med Chem 2007; 7: 461-466.

138 Diamond L, Kimmel EC, Lai YL, et al. Augmentation of elastase-induced emphysema by cigarette smoke. Effects of reduced nicotine content. Am Rev Respir Dis 1988; 138: 1201-1206.

139 Bodas M, Van Westphal C, Carpenter-Thompson R, et al. Nicotine exposure induces bronchial epithelial cell apoptosis and senescence via ROS mediated autophagy-impairment. Free Radic Biol Med 2016; 97: 441-453.

140 Segura-Valdez L, Pardo A, Gaxiola M, et al. Upregulation of gelatinases A and B, collagenases 1 and 2, and increased parenchymal cell death in COPD. Chest 2000; 117: 684-694.

141 Geraghty P, Hardigan A, Foronjy RF. Cigarette smoke activates the proto-oncogene c-src to promote airway inflammation and lung tissue destruction. Am J Respir Cell Mol Biol 2014; 50: 559-570.

142 Iskandar AR, Liu C, Smith DE, et al. $\beta$-cryptoxanthin restores nicotine-reduced lung SIRT1 to normal levels and inhibits nicotine-promoted lung tumorigenesis and emphysema in A/J mice. Cancer Prev Res 2013; 6: 309-320.

143 Nishioka T, Guo J, Yamamoto D, et al. Nicotine, through upregulating pro-survival signaling, cooperates with NNK to promote transformation. J Cell Biochem 2010; 109: 152-161.

144 Hanaki T, Horikoshi Y, Nakaso K, et al. Nicotine enhances the malignant potential of human pancreatic cancer cells via activation of atypical protein kinase C. Biochim Biophys Acta 2016; 1860: 2404-2415.

145 Czyżykowski R, Połowinczak-Przybyłek J, Potemski P. Nicotine-induced resistance of non-small cell lung cancer to treatment - possible mechanisms. Postepy Hig Med Dosw 2016; 70: 186-193.

146 Hao J, Shi FD, Abdelwahab M, et al. Nicotinic receptor $\beta 2$ determines NK cell-dependent metastasis in a murine model of metastatic lung cancer. PLoS One 2013; 8: e57495.

147 Murphy SE, von Weymarn LB, Schutten MM, et al. Chronic nicotine consumption does not influence 4-(methylnitrosamino)-1-(3-pyridyl)-1-butanone-induced lung tumorigenesis. Cancer Prev Res 2011; 4: 1752-1760. 


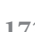

Allen JG, Flanigan SS, LeBlanc M, et al. Flavoring chemicals in e-cigarettes: diacetyl, 2,3-pentanedione, and acetoin in a sample of 51 products, including fruit-, candy-, and cocktail-flavored e-cigarettes. Environ Health Perspect 2016; 124: 733-739.

181 Fujioka K, Shibamoto T. Determination of toxic carbonyl compounds in cigarette smoke. Environ Toxicol 2006; 21: 47-54.

182 Chen IL. FDA summary of adverse events on electronic cigarettes. Nicotine Tob Res 2013; 15: 615-616.

183 Hom S, Chen L, Wang T, et al. Platelet activation, adhesion, inflammation, and aggregation potential are altered

in the presence of electronic cigarette extracts of variable nicotine concentrations. Platelets 2016; 27: 694-702.

Maier CR, Hollander MC, Hobbs EA, et al. Nicotine does not enhance tumorigenesis in mutant K-ras-driven mouse models of lung cancer. Cancer Prev Res 2011; 4: 1743-1751. Sweden. Tob Control 2003; 12: 349-359.

Luo J, Ye W, Zendehdel K, et al. Oral use of Swedish moist snuff (snus) and risk for cancer of the mouth, lung, and pancreas in male construction workers: a retrospective cohort study. Lancet 2007; 369: 2015-2020. Cancer 2016; 139: 2753-2759.

arsalinos KE, Spyrou A, Tsimopoulou K, et al. Nicotine absorption from electronic cigarette use: comparison new-generation devices. Sci Rep 2014; 4: 4133. e-cigarettes. Psychopharmacology 2017; 234: 773-779. 17: $150-157$. profiles and harmful constituent exposures of second-generation and third-generation electronic cigarette users. Tob Control 2017; 26: e23-e28.

Benowitz NL, Burbank AD. Cardiovascular toxicity of nicotine: implications for electronic cigarette use. Trends Cardiovasc Med 2016; 26: 515-523.

infarction. Circulation 2014; 130: 325-332.

prospective observational studies. Eur J Epidemiol 2012; 27: 771-779. patients with cardiac disease. N Engl J Med 1996; 335: 1792-1798. admitted with acute coronary syndromes. Am J Cardiol 2005; 95: 976-978. a network meta-analysis. Circulation 2014; 129: 28-41.

Wallenfeldt K, Hulthe J, Bokemark L, et al. Carotid and femoral atherosclerosis, cardiovascular risk factors and C-reactive protein in relation to smokeless tobacco use or smoking in 58-year-old men. J Intern Med 2001; 250: 492-501. implications for emerging tobacco products. Neurosci Biobehav Rev 2017; 72: 176-189. cigarettes. Ann Plast Surg 2017; 79: 86-91. Callahan-Lyon P. Electronic cigarettes: human health effects. Tob Control 2014; 23: Suppl. 2, ii36-ii40.

Montharu J, Le Guellec S, Kittel B, et al. Evaluation of lung tolerance of ethanol, propylene glycol, and sorbitan monooleate as solvents in medical aerosols. J Aerosol Med Pulm Drug Deliv 2010; 23: 41-46. cigarette smoke. Tob Control 2003; 12: 424-430. Toxicol 2012; 25: 794-810.

Goniewicz ML, Gawron M, Smith DM, et al Exposure to nicotine and selected tox 19: $160-167$.

McRobbie H, Phillips A, Goniewicz ML, et al. Effects of switching to electronic cigarettes with and without concurrent smoking on exposure to nicotine, carbon monoxide, and acrolein. Cancer Prev Res 2015; 8: 873-878. e-cigarette users versus cigarette smokers. Nicotine Tob Res 2015; 17: 704-709.

L, Goniewicz ML, Blount BC, et al. Nicotine, carcinogen, and toxin exposure in ong-term e-cigarette and nicotine replacement therapy users: a cross-sectional study. Ann Intern Med 2017; 166: 390-400. atherogenesis. Arterioscler Thromb Vasc Biol 2014; 34: 509-515. 2013; 10: 219-230 to the scientific statement from the American Heart Association. Circulation 2010; 121: 2331-2378. electronic cigarette cartomizer fluid and aerosol. PLoS One 2013; 8: e57987.

Hess CA, Olmedo P, Navas-Acien A, et al. E-cigarettes as a source of toxic and potentially carcinogenic metals. Environ Res 2017; 152: 221-225.

Farsalinos KE, Gillman G, Poulas K, et al. Tobacco-specific nitrosamines in electronic cigarettes: comparison between liquid and aerosol levels. Int I Environ Res Public Health 2015; 12: 9046-9053. 
Polosa R, Morjaria J, Caponnetto P, et al. Effect of smoking abstinence and reduction in asthmatic smokers switching to electronic cigarettes: evidence for harm reversal. Int J Environ Res Public Health 2014; 11: 4965-4977. Astrid Miler J, Mayer B. Changes in the frequency of airway infections in smokers who switched to vaping: results of an online survey. J Addict Res Ther 2016; 7: doi: 10.4172/2155-6105.1000290.

McConnell R, Barrington-Trimis JL, Wang $\mathrm{K}$, et al. Electronic cigarette use and respiratory symptoms in adolescents. Am J Respir Crit Care Med 2017; 195: 1043-1049.

Monroy AE, Hommel E, Smith ST, et al. Paroxysmal atrial fibrillation following electronic cigarette use in an elderly woman. Clin Geriatr 2012; 20: 28-32.

Kim JW, Baum CR. Liquid nicotine toxicity. Pediatr Emerg Care 2015; 31: 517-521.

Vakkalanka JP, Hardison LS, Holstege CP. Epidemiological trends in electronic cigarette exposures reported to U.S. poison centers. Clin Toxicol 2014; 52: 542-548.

European Regulatory Science on Tobacco (EUREST) Consortium. Study on the Identification of Potential Risks to Public Health Associated with the use of Refillable Electronic Cigarettes and Development of Technical Specifications for Refill Mechanisms. 2016. https://ec.europa.eu/health/sites/health/files/tobacco/docs/potentialrisks_ specs_refillableecigarettes.pdf

Jiwani AZ, Williams JF, Rizzo JA, et al. Thermal injury patterns associated with electronic cigarettes. Int J Burns Trauma 2017; 7: 1-5.

Fromme H, Schober W. Waterpipes and e-cigarettes: impact of alternative smoking techniques on indoor air quality and health. Atmos Environ 2015; 106: 429-441.

Czogala J, Goniewicz ML, Fidelus B, et al. Secondhand exposure to vapors from electronic cigarettes. Nicotine Tob Res 2014; 16: 655-662.

Geiss O, Bianchi I, Barahona F, et al. Characterisation of mainstream and passive vapours emitted by selected electronic cigarettes. Int J Hyg Environ Health 2015; 218: 169-180.

Schober W, Szendrei K, Matzen W, et al. Use of electronic cigarettes (e-cigarettes) impairs indoor air quality and increases FeNO levels of e-cigarette consumers. Int J Hyg Environ Health 2014; 217: 628-637.

Schripp T, Markewitz D, Uhde E, et al. Does e-cigarette consumption cause passive vaping? Indoor Air 2013; 23 25-31.

Melstrom P, Koszowski B, Thanner MH, et al. Measuring PM2.5, ultrafine particles, air nicotine and wipe samples following the use of electronic cigarettes. Nicotine Tob Res 2017; 19: 1055-1061.

McAuley TR, Hopke PK, Zhao J, et al. Comparison of the effects of e-cigarette vapor and cigarette smoke on indoor air quality. Inhal Toxicol 2012; 24: 850-857.

Saffari A, Daher N, Ruprecht A, et al. Particulate metals and organic compounds from electronic and tobacco-containing cigarettes: comparison of emission rates and secondhand exposure. Environ Sci Process Impacts 2014; 16: 2259-2267.

Marco E, Grimalt JO. A rapid method for the chromatographic analysis of volatile organic compounds in exhaled breath of tobacco cigarette and electronic cigarette smokers. J Chromatogr A 2015; 1410: 51-59.

Soule EK, Maloney SF, Spindle TR, et al. Electronic cigarette use and indoor air quality in a natural setting. Tob Control 2017; 26: 109-112.

Kepeis NE, Bellettiere J, Hughes SC, et al. Fine particles in homes of predominantly low-income families with children and smokers: key physical and behavioral determinants to inform indoor-air-quality interventions. PLoS One 2017; 12: e0177718.

Gallart-Mateu D, Elbal L, Armenta S, et al. Passive exposure to nicotine from e-cigarettes. Talanta 2016; 152 329-334.

Jarvis MJ, Russell MA, Feyerabend C, et al. Passive exposure to tobacco smoke: saliva cotinine concentrations in a representative population sample of non-smoking schoolchildren. Br Med J (Clin Res Ed) 1985; 291: 927-929.

Jarvis MJ, Feyerabend C, Bryant A, et al. Passive smoking in the home: plasma cotinine concentrations in non-smokers with smoking partners. Tob Control 2001; 10: 368-374.

St Helen G, Havel C, Dempsey DA, et al. Nicotine delivery, retention and pharmacokinetics from various electronic cigarettes. Addiction 2016; 111: 535-544.

Goniewicz ML, Lee L. Electronic cigarettes are a source of thirdhand exposure to nicotine. Nicotine Tob Res 2015; 17: 256-258.

Destaillats H, Singer BC, Lee SK, et al. Effect of ozone on nicotine desorption from model surfaces: evidence for heterogeneous chemistry. Environ Sci Technol 2006; 40: 1799-1805.

Polosa R, Caponnetto P, Morjaria JB, et al. Effect of an electronic nicotine delivery device (e-cigarette) on smoking reduction and cessation: a prospective 6-month pilot study. BMC Public Health 2011; 11: 786.

Caponnetto P, Campagna D, Cibella F, et al. EffiCiency and Safety of an eLectronic cigAreTte (ECLAT) as tobacco cigarettes substitute: a prospective 12-month randomized control design study. PLoS One 2013; 8: e66317.

Bullen C, Howe C, Laugesen M, et al. Electronic cigarettes for smoking cessation: a randomised controlled trial. Lancet 2013; 382: 1629-1637.

12 Adriaens K, Van Gucht D, Declerck P, et al. Effectiveness of the electronic cigarette: an eight-week Flemish study with six-month follow-up on smoking reduction, craving and experienced benefits and complaints. Int J Environ Res Public Health 2014; 11: 11220-11248.

Hartmann-Boyce J, McRobbie H, Bullen C, et al. Electronic cigarettes for smoking cessation. Cochrane Database Syst Rev 2016; 9: CD010216.

Stead LF, Perera R, Bullen C, et al. Nicotine replacement therapy for smoking cessation. Cochrane Database Syst Rev 2012; 11: CD000146.

Pacifici R, Pichini S, Graziano S, et al. Successful nicotine intake in medical assisted use of e-cigarettes: a pilot study. Int J Environ Res Public Health 2015; 12: 7638-7646.

Polosa R, Caponnetto P, Maglia M, et al. Success rates with nicotine personal vaporizers: a prospective 6-month pilot study of smokers not intending to quit. BMC Public Health 2014; 14: 1159.

Polosa R, Caponnetto P, Cibella F, et al. Quit and smoking reduction rates in vape shop consumers: a prospective 12-month survey. Int J Environ Res Public Health 2015; 12: 3428-3438.

jek P, Corbin L, Ladmore D, et al. Adding e-cigarettes to specialist stop-smoking treatment: City of London pilot project. J Addict Res Ther 2015; 6: 244. 

in schizophrenic smokers: a prospective 12-month pilot study. Int J Environ Res Public Health 2013; 10: 446-461. Halpern SD, Harhay MO, Saulsgiver K, et al. A pragmatic trial of e-cigarettes, incentives, and drugs for smoking cessation. N Engl J Med 2018; 378: 2302-2310.

221 Beard E, West R, Michie S, et al. Association between electronic cigarette use and changes in quit attempts, success of quit attempts, use of smoking cessation pharmacotherapy, and use of stop smoking services in England: time series analysis of population trends. BMJ 2016; 354: i4645.

222 West R, Shahab L, Brown J. Estimating the population impact of e-cigarettes on smoking cessation in England. Addiction 2016; 111: 1118-1119.

223 Action on Smoking and Health (ASH). Use of E-Cigarettes (Vapourisers) Among Adults in Great Britain. September 2018. http://ash.org.uk/download/use-of-e-cigarettes-among-adults-in-great-britain-2017

224 E-Cigarette Use Among Youth and Young Adults: A Report of the Surgeon General. Atlanta, U.S. Department of Health and Human Services, 2016.

225 Dautzenberg B, de Souza Moura M-A, Rieu N, et al. L'e-cigarette bouleverse les autres consommations des adolescents parisiens (2012 à 2014). [The e-cigarette disrupts other consumptions in Parisian teenagers (2012-2014)]. Rev Mal Respir 2016; 33: 225-234.

226 Lifestyles Statistics Team, Health and Social Care Information Centre. Statistics on Smoking: England 2015. Health and Social Care Information Centre, 2015.

227 Miech RA, Johnston LD, O'Malley PM, et al. Monitoring the Future National Survey Results on Drug Use, 19752015. Ann Arbor, Institute for Social Research, The University of Michigan, 2016.

228 Zhu SH, Zhuang YL, Wong S, et al. E-cigarette use and associated changes in population smoking cessation: evidence from US current population surveys. BMJ 2017; 358: j3262.

229 Brown J, Beard E, Kotz D, et al. Real-world effectiveness of e-cigarettes when used to aid smoking cessation: a cross-sectional population study. Addiction 2014; 109: 1531-1540.

230 NHS Digital. Statistics on NHS Stop Smoking Services: England, April 2015 to March 2016. https://files.digital. nhs.uk/publicationimport/pub21xxx/pub21162/stat-stop-smok-serv-eng-q4-1516-rep.pdf

231 Kalkhoran S, Glantz SA. E-cigarettes and smoking cessation in real-world and clinical settings: a systematic review and meta-analysis. Lancet Respir Med 2016; 4: 116-128.

232 Royal College of Physicians (RCP). Nicotine Without Smoke: Tobacco Harm Reduction. London, RCP, 2016.

233 Weaver SR, Huang J, Pechacek TF, et al. Are electronic nicotine delivery systems helping cigarette smokers quit? Evidence from a prospective cohort study of U.S. adult smokers, 2015-2016. PloS One 2018; 13: e0198047.

234 Maloney EK, Cappella JN. Does vaping in e-cigarette advertisements affect tobacco smoking urge, intentions, and perceptions in daily, intermittent, and former smokers? Health Commun 2016; 31: 129-138.

235 Barrington-Trimis JL, Berhane K, Unger JB, et al. The e-cigarette social environment, e-cigarette use, and susceptibility to cigarette smoking. J Adolesc Health 2016; 59: 75-80.

236 Rass O, Pacek LR, Johnson PS, et al. Characterizing use patterns and perceptions of relative harm in dual users of electronic and tobacco cigarettes. Exp Clin Psychopharmacol 2015; 23: 494-503.

237 Schmidt L, Reidmohr A, Harwell TS, et al. Prevalence and reasons for initiating use of electronic cigarettes among adults in Montana, 2013. Prev Chronic Dis 2014; 11: E204.

238 Harrell PT, Simmons VN, Piñeiro B, et al. E-cigarettes and expectancies: why do some users keep smoking? Addiction 2015; 110: 1833-1843.

239 Piñeiro B, Correa JB, Simmons VN, et al. Gender differences in use and expectancies of e-cigarettes: online survey results. Addict Behav 2016; 52: 91-97.

240 Gallus S, Lugo A, Pacifici R, et al. E-cigarette awareness, use, and harm perceptions in Italy: a national representative survey. Nicotine Tob Res 2014; 16: 1541-1548.

241 Brown-Johnson CG, Popova L. Exploring smoking stigma, alternative tobacco product use, \& quit attempts. Health Behav Policy Rev 2016; 3: 13-20.

242 Pulvers K, Hayes RB, Scheuermann TS, et al. Tobacco use, quitting behavior, and health characteristics among current electronic cigarette users in a national tri-ethnic adult stable smoker sample. Nicotine Tob Res 2015; 17: 1085-1095.

243 Lechner WV, Tackett AP, Grant DM, et al. Effects of duration of electronic cigarette use. Nicotine Tob Res 2015; 17: $180-185$.

244 Hitchman SC, Brose LS, Brown J, et al. Associations between e-cigarette type, frequency of use, and quitting smoking: findings from a longitudinal online panel survey in Great Britain. Nicotine Tob Res 2015; 17: 1187-1194.

245 Biener L, Hargraves JL. A longitudinal study of electronic cigarette use among a population-based sample of adult smokers: association with smoking cessation and motivation to quit. Nicotine Tob Res 2015; 17: $127-133$.

246 Grace RC, Kivell BM, Laugesen M. Estimating cross-price elasticity of e-cigarettes using a simulated demand procedure. Nicotine Tob Res 2015; 17: 592-598.

247 Farsalinos KE, Romagna G, Voudris V. Factors associated with dual use of tobacco and electronic cigarettes: a case control study. Int J Drug Policy 2015; 26: 595-600.

248 Sutfin EL, McCoy TP, Morrell HE, et al. Electronic cigarette use by college students. Drug Alcohol Depend 2013; 131: $214-221$

249 Saddleson ML, Kozlowski LT, Giovino GA, et al. Enjoyment and other reasons for electronic cigarette use: results from college students in New York. Addict Behav 2016; 54: 33-39.

250 Soneji S, Sargent J, Tanski S. Multiple tobacco product use among US adolescents and young adults. Tob Control 2016; 25: 174-180.

251 Cooper M, Case KR, Loukas A, et al. E-cigarette dual users, exclusive users and perceptions of tobacco products. Am J Health Behav 2016; 40: 108-116.

252 Goniewicz ML, Leigh NJ, Gawron M, et al. Dual use of electronic and tobacco cigarettes among adolescents: a cross-sectional study in Poland. Int J Public Health 2016; 61: 189-197.

253 Rüther T, Wissen F, Linhardt A, et al. Electronic cigarettes - attitudes and use in Germany. Nicotine Tob Res 2016; 18: 660-669.

254 Coleman BN, Apelberg BJ, Ambrose BK, et al. Association between electronic cigarette use and openness to cigarette smoking among US young adults. Nicotine Tob Res 2015; 17: 212-218. 
Moore GF, Littlecott HJ, Moore L, et al. E-cigarette use and intentions to smoke among 10-11-year-old never-smokers in Wales. Tob Control 2016; 25: 147-152.

Primack BA, Soneji S, Stoolmiller M, et al. Progression to traditional cigarette smoking after electronic cigarette use among US adolescents and young adults. JAMA Pediatr 2015; 169: 1018-1023.

Wills TA, Sargent JD, Knight R, et al. E-cigarette use and willingness to smoke: a sample of adolescent non-smokers. Tob Control 2016; 25: e52-e59.

Best C, Haseen F, Currie D, et al. Relationship between trying an electronic cigarette and subsequent cigarette experimentation in Scottish adolescents: a cohort study. Tob Control 2017; doi: 10.1136/tobaccocontrol-2017-053691. Trumbo CW, Harper R. Use and perception of electronic cigarettes among college students. J Am Coll Health 2013; 61: 149-155.

Best C, van der Sluijs W, Haseen F, et al. Does exposure to cigarette brands increase the likelihood of adolescent e-cigarette use? A cross-sectional study. BMJ Open 2016; 6: e008734.

Cardenas VM, Evans VL, Balamurugan A, et al. Use of electronic nicotine delivery systems and recent initiation of smoking among US youth. Int J Public Health 2016; 61: 237-241.

Hughes K, Bellis MA, Hardcastle KA, et al. Associations between e-cigarette access and smoking and drinking behaviours in teenagers. BMC Public Health 2015; 15: 244.

Kinnunen JM, Ollila H, El-Tayeb El-Amin S, et al. Awareness and determinants of electronic cigarette use among Finnish adolescents in 2013: a population-based study. Tob Control 2015; 24: e264-e270.

Lessard J, Henrie J, Livingston JA, et al. Correlates of ever having used electronic cigarettes among older adolescent children of alcoholic fathers. Nicotine Tob Res 2014; 16: 1656-1660.

Saddleson ML, Kozlowski LT, Giovino GA, et al. Risky behaviors, e-cigarette use and susceptibility of use among college students. Drug Alcohol Depend 2015; 149: 25-30.

Stenger N, Chailleux E. Enquête sur l'usage de la cigarette électronique et du tabac en milieu scolaire. [Survey on the use of electronic cigarettes and tobacco among children in middle and high school]. Rev Mal Respir 2015; 33: 56-62. Meier EM, Tackett AP, Miller MB, et al. Which nicotine products are gateways to regular use? First-tried tobacco and current use in college students. Am J Prev Med 2015; 48: S86-S93.

Sutfin EL, Reboussin BA, Debinski B, et al. The impact of trying electronic cigarettes on cigarette smoking by college students: a prospective analysis. Am J Public Health 2015; 105: e83-e89.

Leventhal AM, Strong DR, Kirkpatrick MG, et al. Association of electronic cigarette use with initiation of combustible tobacco product smoking in early adolescence. JAMA 2015; 314: 700-707.

Barrington-Trimis JL, Urman R, Berhane K, et al. E-cigarettes and future cigarette use. Pediatrics 2016; 138: e20160379.

Soneji S, Barrington-Trimis JL, Wills TA, et al. Association between initial use of e-cigarettes and subsequent cigarette smoking among adolescents and young adults: a systematic review and meta-analysis. JAMA Pediatr 2017; 171: 788-797.

Zhong J, Cao S, Gong W, et al. Electronic cigarettes use and intention to cigarette smoking among never-smoking adolescents and young adults: a meta-analysis. Int J Environ Res Public Health 2016; 13: E465.

Etter JF. Gateway effects and electronic cigarettes. Addiction 2018; 113: 1776-1783.

Kristjansson AL, Mann MJ, Sigfusdottir ID. Licit and illicit substance use by adolescent e-cigarette users compared with conventional cigarette smokers, dual users, and nonusers. J Adolesc Health 2015; 57: 562-564.

Hampson SE, Andrews JA, Severson HH, et al. Prospective predictors of novel tobacco and nicotine product use in emerging adulthood. $J$ Adolesc Health 2015; 57: 186-191.

Pentz MA, Shin H, Riggs N, et al. Parent, peer, and executive function relationships to early adolescent e-cigarette use: a substance use pathway? Addict Behav 2015; 42: 73-78.

Biener L, Song E, Sutfin EL, et al. Electronic cigarette trial and use among young adults: reasons for trial and cessation of vaping. Int J Environ Res Public Health 2015; 12: 16019-16026.

Coleman BN, Johnson SE, Tessman GK, et al. "It's not smoke. It's not tar. It's not 4000 chemicals. Case closed": exploring attitudes, beliefs, and perceived social norms of e-cigarette use among adult users. Drug Alcohol Depend 2016; 159: 80-85.

9 Farsalinos KE, Romagna G, Tsiapras D, et al. Characteristics, perceived side effects and benefits of electronic cigarette use: a worldwide survey of more than 19,000 consumers. Int J Environ Res Public Health 2014; 11: 4356-4373.

Harrell PT, Marquinez NS, Correa JB, et al. Expectancies for cigarettes, e-cigarettes, and nicotine replacement therapies among e-cigarette users (aka vapers). Nicotine Tob Res 2015; 17: 193-200.

Hendricks PS, Cases MG, Thorne CB, et al. Hospitalized smokers' expectancies for electronic cigarettes versus tobacco cigarettes. Addict Behav 2015; 41: 106-111.

Farsalinos KE, Romagna G, Tsiapras D, et al. Impact of flavour variability on electronic cigarette use experience: an internet survey. Int J Environ Res Public Health 2013; 10: 7272-7282.

Goniewicz ML, Lingas EO, Hajek P. Patterns of electronic cigarette use and user beliefs about their safety and benefits: an internet survey. Drug Alcohol Rev 2013; 32: 133-140.

McDonald EA, Ling PM. One of several "toys" for smoking: young adult experiences with electronic cigarettes in New York City. Tob Control 2015; 24: 588-593.

Pokhrel P, Herzog TA, Muranaka N, et al. Young adult e-cigarette users' reasons for liking and not liking e-cigarettes: a qualitative study. Psychol Health 2015; 30: 1450-1469.

Rooke C, Cunningham-Burley S, Amos A. Smokers' and ex-smokers' understanding of electronic cigarettes: a qualitative study. Tob Control 2016; 25: e60-e66.

Etter J-F. Electronic cigarettes: a survey of users. BMC Public Health 2010; 10: 231.

Nădăşan V, Foley KL, Pénzes M, et al. Use of electronic cigarettes and alternative tobacco products among Romanian adolescents. Int J Public Health 2016; 61: 199-207.

Union member states. Tob Control 2017; 26: 98-104.

Berg CJ. Preferred flavors and reasons for e-cigarette use and discontinued use among never, current, and former smokers. Int J Public Health 2016; 61: 225-236.

Gaga M, Welte T, Troosters T, et al. Rapid response: Electronic cigarettes for smoking cessation. BMJ 2018 ; 360 : j5543. 